\title{
Vegetation Change and Its Response to Climate Change in Yunnan Province, China
}

\author{
Huaizhang Sun $\mathbb{D}^{10,2}$ Jiyan Wang, ${ }^{1}$ Junnan Xiong $\mathbb{D}^{1,3}$ Jinhu Bian, ${ }^{2}$ Huaan Jin, ${ }^{2}$ \\ Weiming Cheng, ${ }^{3,4}$ and Ainong $\mathrm{Li}^{2}$ \\ ${ }^{1}$ School of Civil Engineering and Geomatics, Southwest Petroleum University, Chengdu 610500, China \\ ${ }^{2}$ Institute of Mountain Hazards and Environment, Chinese Academy of Sciences, Chengdu 610041, China \\ ${ }^{3}$ State Key Laboratory of Resources and Environmental Information System, \\ Institute of Geographic Sciences and Natural Resources Research, CAS, Beijing 100101, China \\ ${ }^{4}$ University of Chinese Academy of Sciences, Beijing 100049, China \\ Correspondence should be addressed to Junnan Xiong; neu_xjn@163.com
}

Received 21 September 2020; Accepted 2 January 2021; Published 4 February 2021

Academic Editor: Herminia García Mozo

Copyright ( $\odot 2021$ Huaizhang Sun et al. This is an open access article distributed under the Creative Commons Attribution License, which permits unrestricted use, distribution, and reproduction in any medium, provided the original work is properly cited.

\begin{abstract}
The impact of global climate change on vegetation has become increasingly prominent over the past several decades. Understanding vegetation change and its response to climate can provide fundamental information for environmental resource management. In recent years, the arid climate and fragile ecosystem have led to great changes in vegetation in Yunnan Province, so it is very important to further study the relationship between vegetation and climate. In this study, we explored the temporal changes of normalized difference vegetation index (NDVI) in different seasons based on MOD13Q1 NDVI by the maximum value composite and then analyzed spatial distribution characteristics of vegetation using Sen's tendency estimation, Mann-Kendall significance test, and coefficient of variation model (CV) combined with terrain factors. Finally, the concurrent and lagged effects of NDVI on climate factors in different seasons and months were discussed using the Pearson correlation coefficient. The results indicate that (1) the temporal variation of the NDVI showed that the NDVI values of different vegetation types increased at different rates, especially in growing season, spring, and autumn; (2) for spatial patterns, the NDVI, CV, and NDVI trends had strong spatial heterogeneity owning to the influence of altitudes, slopes, and aspects; and (3) the concurrent effect of vegetation on climate change indicates that the positive effect of temperature on NDVI was mainly in growing season and autumn, whereas spring NDVI was mainly influenced by precipitation. In addition, the lag effect analysis results revealed that spring precipitation has a definite inhibition effect on summer and autumn vegetation, but spring and summer temperature can promote the growth of vegetation. Meanwhile, the precipitation in the late growing season has a lag effect of 1-2 months on vegetation growth, and air temperature has a lag effect of 1 month in the middle of the growing season. Based on the above results, this study provided valuable information for ecosystem degradation and ecological environment protection in the Yunnan Province.
\end{abstract}

\section{Introduction}

As a key component of terrestrial ecosystems, vegetation plays a pivotal role in the linkage of the pedosphere, atmosphere, and hydrosphere $[1,2]$. It affects the carbon cycle, energy exchange, climate change, and the water cycle of the diverse ecosystems in direct or indirect ways [3]. However, global warming, unreasonable human disturbance [4], deforestation, wetland shrinkage, grassland degradation, encroachment upon farmlands, and desertification have given rise to the temporal and spatial atrophy of vegetation in diverse ecosystems [5]. Dynamically monitoring the vegetation changes of terrestrial ecosystems is critical to understand the role in the global material cycle and energy flow and to provide a theory for humans to natural resources in a reasonable manner.

With the development of satellite sensor technology, remote sensing techniques have been widely used to monitor vegetation growth because of a large coverage area and long time series [6]. Good relationships between the vegetation 
indices and vegetation coverage have been reported, and vegetation indices, such as the normalized difference vegetation index (NDVI), are usually used to explore the ability of remote sensing data to evaluate vegetation variety $[7,8]$. For example, $\mathrm{Wu}$ et al. employed the time series of NDVI data to monitor the spatial distribution of global vegetation and the time-lag effects of the vegetation responses to climatic factors [9]. Shilong et al. investigated the temporal patterns of vegetation in temperate and boreal regions of Eurasia $\left(>23.5^{\circ}\right)$ based on the NDVI from 1982 to 2006 [10]. Liu and Lei applied the NDVI to study the temporal and spatial distribution of vegetation in China during 1982-2011 [2]. Zhang et al. explored the spatiotemporal patterns of vegetation growth in the Koshi River Basin in the middle Himalayas during 1982-2011 [11]. These studies indicated that the NDVI was able to examine the temporal and spatial variations of vegetation at different temporal and spatial scales. Therefore, it is feasible to employ the NDVI to explore the spatial and temporal characteristics of vegetation in a long, continuous time series.

In recent years, some studies have been conducted on the spatiotemporal distribution of vegetation and its relationship with climate factors, although some problems still remain. First, at present, unitary linear regression is mostly used to analyze interannual changes in vegetation in research on vegetation change trends, but this method has a weak ability to avoid errors [12]. Meanwhile, researchers usually use a threshold to classify statistical data when using unitary linear regression. Although the results can be classified in more detail, it is difficult to give a statistical explanation $[13,14]$. Second, most previous studies mainly paid more attention to the mean NDVI values within a fixed time period (such as a whole year or growing season), which may not properly reflect the seasonal differences in the relationship between vegetation and climate change $[2,15]$. Yunnan has a complex and diverse climate. The seasonal climate of Yunnan Province is very different because of the influence of the East Asian monsoon, the Indian monsoon, and air masses from the Tibet Plateau [16]. The precipitation is mainly concentrated in summer (accounting for more than half of the annual precipitation) and less concentrated in spring [17]. For temperature in Yunnan Province, the warming rate in winter $\left(0.33^{\circ} \mathrm{C}\right.$ per decade $)$ is faster than that in summer $\left(0.26^{\circ} \mathrm{C}\right.$ per decade) [18]. There is a wide range of vegetation types in Yunnan, and the growth periods of different regions and vegetation types are significantly different. Thus, vegetation changes and their response to climate on the seasonal scale must be considered. Third, vegetation needs a period of time to adapt to climate change, so the lag effects should not be ignored when analyzing the relationship between seasonal vegetation changes and climate factors. The lag effects of vegetation responses to climate change are caused by climate change exceeding the ability of vegetation ability to adapt to environmental disturbances $[19,20]$. In order to improve the accuracy of the relationship between vegetation activity and climate factors, the lag effects should be considered. Hence, to deeply understand the response of vegetation variation to climate change in arid and semiarid areas, the specific case study is still necessary by using the NDVI in more detail.

This paper takes Yunnan Province as a case study, with the goal of assessing the spatiotemporal changes in vegetation and its response to climate change. The specific objectives of this study were the following: (1) to explore the spatiotemporal patterns of vegetation growth in Yunnan Province and the mechanisms of vegetation change using the maximum value composite, Mann-Kendall (M-K) abrupt change test, Sen's tendency estimation, M-K significance test, and coefficient of variation (CV) model; (2) to analyze the concurrent effects of climate change on vegetation for different seasons; and (3) to explore the time-lag effects of vegetation activity responses to climatic factors at the season scale.

\section{Materials and Methods}

2.1. Study Area. Yunnan Province $\left(20^{\circ} 8^{\prime}-29^{\circ} 16^{\prime} \mathrm{N}\right.$, $97^{\circ} 31^{\prime}-106^{\circ} 12^{\prime} \mathrm{E}$ ), located in southwest China, bordering the Xizang Plateau and the Himalayan Range on the west and Laos and Vietnam on the south [21], covers an area of approximately $3.83 \times 10^{5} \mathrm{~km}^{2}$ (Figure 1). The elevation of this region increases from $76 \mathrm{~m}$ in the southeast to $6,740 \mathrm{~m}$ in the northwest, with an average altitude of 2,000 $\mathrm{m}$ [22]. The region contains various terrains, with karst landscape in the east, deep canyons in the west, and longitudinal mountains throughout the area [16]. It is particularly worth mentioning that Yunnan Province is called the "kingdom of plants" for its rich plant diversity and is one of the most biodiverse areas in China [23]. The main vegetation types in Yunnan Province are woodland, cultivated plant, shrubland, grassland, and meadow steppes, which accounts for $27.04 \%$, $26.01 \%, 22.51 \%, 21.14 \%$, and $2.60 \%$ of the area of Yunnan, respectively.

The climate of Yunnan Province is a typical plateau monsoon climate, which is affected by the East Asian monsoon, the Indian monsoon, and air masses from the Tibet Plateau with abundant rainfall but an uneven spatiotemporal distribution (ranging from 560 to $2,300 \mathrm{~mm}$ ) [16]. The annual average precipitation is approximately $1,100 \mathrm{~mm}$, which is primarily concentrated between June and August in Yunnan Province [24]. Furthermore, the precipitation has increased in recent years in the central and northwest of Yunnan Province [25]. Yunnan Province has a relatively small annual temperature variation because of its cold zone, temperate zone, and tropical climate types. The average temperature of the hottest month (July) is between $19^{\circ} \mathrm{C}$ and $22^{\circ} \mathrm{C}$, and that of the coldest month (January) is over $6^{\circ} \mathrm{C}$ [26]. However, Yunnan Province has a large daily temperature difference. All these conditions have contributed to make this study area a popular region for the study of the relationship between vegetation and climate.

2.2. Data Compilation. In this study, time-series NDVI (MOD13Q1) data from National Aeronautics and Space Administration (NASA) (https://ladsweb.modaps.eosdis. nasa.gov/) were used to explore the spatiotemporal 


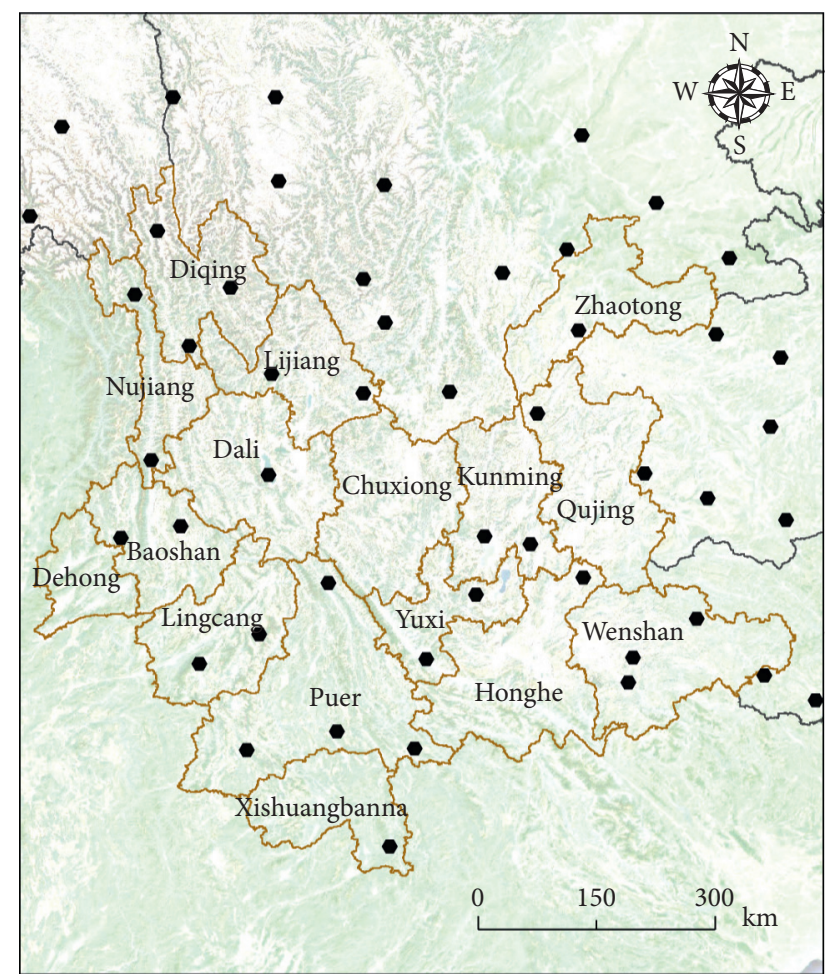

\section{City boundary \\ Provincial boundary}

- Meteorological stations

(a)

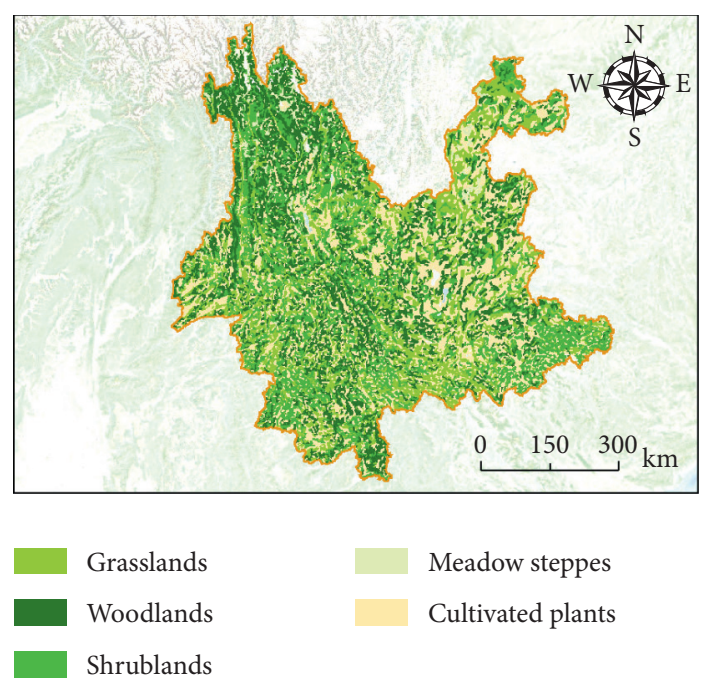

(c)

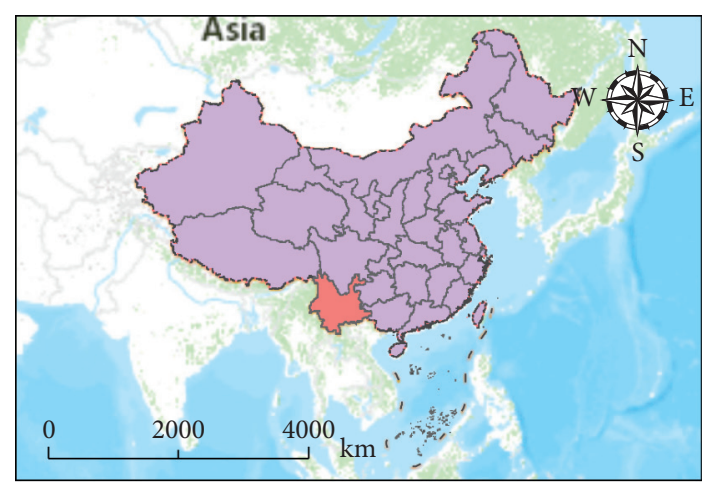

(b)

Figure 1: The study area across Yunnan Province.

distribution of the vegetation, with a temporal resolution of 16 days and a spatial resolution of $250 \mathrm{~m} \times 250 \mathrm{~m}$. The data were processed with radiation, atmospheric, and geometric corrections to guarantee that they are of high quality, and it has been widely used in the study of regional vegetation.
The meteorological data (monthly precipitation and air temperature) from 2001 to 2018 for 52 nationally standard meteorological stations around and within the study area (see Figure 1) were provided by the Chinese Meteorological Administration (http://data.cma.cn/). The spatial distribution of precipitation and air temperature in the entire region 
was predicted using Kriging interpolation in ARCGIS 10.5. In addition, we obtained the seasonal precipitation and air temperature distribution over the past 18 years through monthly precipitation and air temperature based on a raster calculator in ARCGIS 10.5.

Vegetation types of Yunnan in this study were extracted from the $1: 1,000,000$ China vegetation map published by the Data Center of Chinese Academy of Resources and Environmental Sciences (http://www.resdc.cn/) and reclassified into five categories, namely, woodland, cultivated plant, shrubland, grassland, and meadow steppes. In addition, the spatial pattern of these major vegetation types is shown in Figure 1.

ASTER digital elevation model (DEM) data were collected from NASA (https://asterweb.jpl.nasa.gov/ gdem.asp) with a spatial resolution of $30 \mathrm{~m}$. The slope and aspect were calculated by ARCGIS10.5 based on the DEM.

2.3. Study Method. For this paper, the temporal changes of NDVI in different seasons (growing season, spring, summer, and autumn) were analyzed based on MODIS13Q1 NDVI by maximum value composite. Then, the spatial distribution characteristics of vegetation were explored using Sen's tendency estimation, M-K significance test, and CV model combined with terrain factors (altitude, slope, and aspect). Finally, we analyzed the concurrent and lagged effects of NDVI on climate factors in different seasons and months using the Pearson correlation coefficient.

2.3.1. Maximum Value Composite. The maximum value composite was proposed by Holben, which has the advantages of minimizing the effects of cloud contamination, atmosphere scan angle, and solar zenith angle [13, 27]. For this study, the maximum value composite method was used to reconstruct the original NDVI data into the seasonal or monthly NDVI dataset. The equation to calculate maximum NDVI is as follows:

$$
\text { MNDVI }=\max _{i}^{n}\left(\mathrm{NDVI}_{j}\right), \quad i \leq j \leq n,
$$

where MNDVI represents the maximum NDVI value in different seasons or months, $i$ represents the sequence number of the first image of each season or month, and $n$ represents the sequence number of the last image of each season or month.

2.3.2. Sen's Tendency Estimation. Sen slope estimation method was proposed by Sen et al. for the purpose of analyzing the slope trend of time-series data $[12,28]$. It is a mathematical statistical method that has the following advantage: even the absence of data or the existence of bad points in individual data series does not affect the trend result. For this study, the slope trend of the NDVI time series was calculated by Sen's tendency estimation method. The formula is as follows:

$$
\text { slope }=\operatorname{median}\left[\frac{\left(x_{j}-x_{i}\right)}{(j-i)}\right], \quad \forall j>i,
$$

where $x_{i}$ and $x_{j}$ are the values at times $i$ and $j$, respectively, and slope is the tendency of NDVI time series. Slope $>0$ indicates an upward trend and slope $<0$ means the downward trend.

2.3.3. M-K Significance Test. In this study, since Sen's tendency estimation method lacks statistical significance testing for the trend, we evaluated it using the M-K significance test method. As a nonparametric statistical test, this method does not require the sample data to obey a certain distribution and is not affected by outliers, so it is widely used to identify a monotonic trend in climate. The $\mathrm{M}-\mathrm{K}$ significance test is given as follows $[12,28]$ :

$$
\begin{aligned}
& Z=\left\{\begin{array}{cl}
\frac{S-1}{\sqrt{\operatorname{var}(S)},} & S>0, \\
\frac{S+1}{\sqrt{\operatorname{var}(S)},} & S<0,
\end{array}\right. \\
& S=\sum_{j=1}^{n-1} \sum_{i=j=1}^{n} \operatorname{sgn}\left(\mathrm{NDVI}_{j}-\mathrm{NDVI}_{i}\right) \\
& \operatorname{sgn}\left(\mathrm{NDVI}_{j}-\mathrm{NDVI}_{i}\right)= \begin{cases}1, & \mathrm{NDVI}_{j}-\mathrm{NDVI}_{i}>0, \\
0, & \mathrm{NDVI}_{j}-\mathrm{NDVI}_{i}=0, \\
-1, & \mathrm{NDVI}_{j}-\mathrm{NDVI}_{i}<0,\end{cases} \\
& \operatorname{var}(S)=\frac{n(n-1)(2 n+5)}{18},
\end{aligned}
$$

where $\mathrm{NDVI}_{i}$ and $\mathrm{NDVI}_{j}$ are the values of the pixels in the $i$ th and $j$ th years, respectively, and $n$ indicates the length of the time series. $Z$ obeys a standard normal distribution, and its value ranges from $-\infty$ to $+\infty$. When the calculated result of $Z$ is greater than 0 , it indicates an upward trend. When the calculated result of $Z$ is less than 0 , it indicates a downward trend. Under the given significance, if $|Z|>Z 1-\alpha / 2$, the trend is considered to be significant. When $|Z|>2.58$, it indicates that the linear trend has passed the significance test of 0.01 , whereas when $|Z|>1.96$, it indicates that it has passed the significance test of 0.05. In this study, the NDVI trend categories are shown in Table 1 based on Sen's tendency estimation and the M-K significance test.

2.3.4. CV Model. The CV method is a statistical method for measuring the degree of variation of each observation in a group of observations. In this paper, based on the pixel scale, this model is used to perform statistical analysis on the degree of variation of NDVI in time series and to evaluate 
TABLE 1: Classified result of NDVI change simulated from 2001 to 2018.

\begin{tabular}{lcc}
\hline Items & The trend of NDVI change & Status \\
\hline & Slope $<0, P<0.01$ & Extremely significant \\
Slope $<0,0.01 \leq P<0.05$ & Significant decrease \\
Category & Slope $<0,0.05 \leq P$ & Insignificant decrease \\
& Slope $>0,0.05 \leq P$ & Insignificant increase \\
& Slope $>0,0.01 \leq P<0.05$ & Significant increase \\
Slope $>0, P<0.01$ & Extremely significant \\
increase
\end{tabular}

the stability of NDVI with time. The calculation formula is as follows [29]:

$$
\mathrm{CV}=\frac{\sqrt{\sum_{1}^{n}(\mathrm{NDVI}-\overline{\mathrm{NDVI}})^{2}}}{\overline{\mathrm{NDVI}}},
$$

where $\overline{\text { NDVI }}$ is the average value of a pixel from 2001 to 2018. The larger CV value represents the fiercer fluctuation of NDVI. On the contrary, the smaller CV value means the slighter fluctuation of NDVI [30].

2.3.5. Pearson Correlation Coefficient. Vegetation has certain adaptability to climate change. Sometimes, vegetation does not change immediately with climate change, that is, the response of vegetation to climate change has a certain time lag. The NDVI sequence in the study area from 2001 to 2018 and the mean precipitation sequence were taken as two groups of variables for calculating the correlation coefficient between NDVI and mean precipitation. Similarly, in order to calculate the correlation coefficient between the NDVI sequence and the mean air temperature, we use two groups of variables: mean air temperature and NDVI. To explore the concurrent and lag effects of NDVI on different seasonal and monthly climate factors, we compared the seasonal or monthly correlation coefficients between NDVI and climate factors in different seasons and months. The relevant formula is as follows [31]:

$$
R_{x y}=\frac{\sum_{i=1}^{n}\left[\left[x_{i}-\bar{x}\right] \cdot\left[y_{i}-\bar{y}\right]\right]}{\sqrt{\sum_{i=1}^{n}\left[\left[x_{i}-\bar{x}\right]^{2} \cdot\left[y_{i}-\bar{y}\right]^{2}\right]}},
$$

where $R_{x y}$ is the correlation coefficient between $x$ and $y$ and $n$ is the number of years during the study. The correlation coefficient levels are shown in Table 2.

\section{Results}

\subsection{Spatiotemporal Patterns of NDVI}

3.1.1. Interannual Variation of NDVI in Different Vegetation Types. In order to investigate the time-series variation of NDVI in different vegetation types in Yunnan Province from 2001 to 2018, the seasonal time scale was analyzed (Figure 2). Specifically, the vegetation type with the largest NDVI value is woodland, followed by shrubland, grassland, cultivated
TABle 2: Pearson correlation coefficient and corresponding correlation levels.

\begin{tabular}{lc}
\hline$P$ and $R_{x y}$ value & Correlation level \\
\hline$R_{x y}<0, P<0.01$ & Extremely significant negative correlation \\
$R_{x y}<0,0.01 \leq P<0.05$ & Significant negative correlation \\
$R_{x y}<0,0.05 \leq P$ & Insignificant negative correlation \\
$R_{x y}>0, P<0.01$ & Extremely significant positive correlation \\
$R_{x y}>0,0.01 \leq P<0.05$ & Significant positive correlation \\
$R_{x y}>0,0.05 \leq P$ & Insignificant positive correlation \\
\hline
\end{tabular}

steppe, and meadow steppe in the growing season, spring, and autumn. However, NDVI values of forest, grassland, cultivated steppes, and shrubland are almost the same in summer, and the NDVI value of meadow steppes is the lowest. In addition, during the study period, NDVI values of different vegetation types increased at different rates in growing season, spring, and autumn. However, the NDVI values of each vegetation type showed a relatively flat trend in summer, and only meadow steppes showed a large range of change.

3.1.2. Characteristics of Spatial Distribution of NDVI. The growing season NDVI from 2001 to 2018 of Yunnan Province showed a distribution pattern that decreased from the southwest to northeast (Figure 3(a)). The high-value areas of growing season NDVI were mainly distributed in Xishuangbanna, Dehong, Puer, Lincang, and Baoshan (Figure 3(b)). Low-value areas were mainly concentrated in Kunming, Lijiang, Qujing, Yuxi, Chuxiong, Dali, and Diqing. The results of trend analysis showed that growing season NDVI had mainly an insignificant increase (48.97\%), followed by insignificant decrease (16.95\%), extremely significant increase (15.98\%), significant increase (15.81\%), significant decrease $(1.31 \%)$, and extremely significant decrease $(0.98 \%)$ (Table 3$)$. The areas with a significant increase and an extremely significant increase were mainly concentrated in Zhaotong, Qujing, Wenshan, Puer, and Lincang (Figure 3(c)). The areas with significant decrease and extremely significant decrease were mainly distributed in Kunming, Yuxi, Diqing, Lijiang, and Dali. The stability analysis results showed that growing season NDVI in Yunnan Province from 2001 to 2018 was generally stable, with $\mathrm{CV}$ values ranging from 0 to 3.36 (Figure $3(\mathrm{~d})$ ). At the pixel scale, the high-value areas of CV were primarily distributed in Kunming, Yuxi, and Diqing, which indicates that the growing season NDVI varied wildly and fluctuated greatly in these areas.

3.1.3. The Relationship between Terrain Factor and NDVI, $C V$, and NDVI Trends. In this study, the relationship between terrain factor and NDVI, CV, and NDVI trends is shown in Figure 4. NDVI generally showed a decreasing trend with an increase in altitude (Figure 4(a)). Specifically, with the increase of altitude, NDVI first increased and then decreased, and the value of NDVI reached its maximum at an altitude of 500-1000 m. On the contrary, NDVI increased as sloped increased (Figure 4(b)). In addition, the 


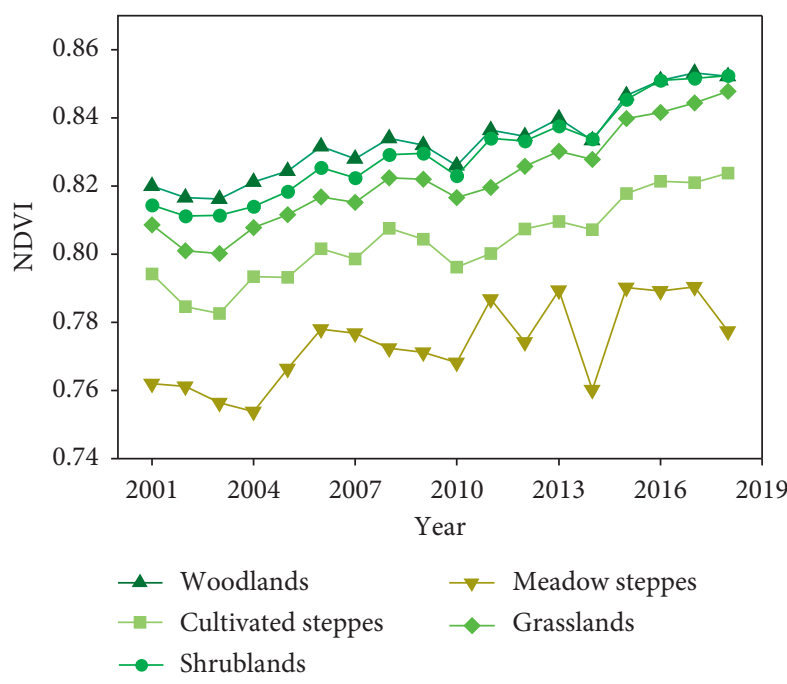

(a)

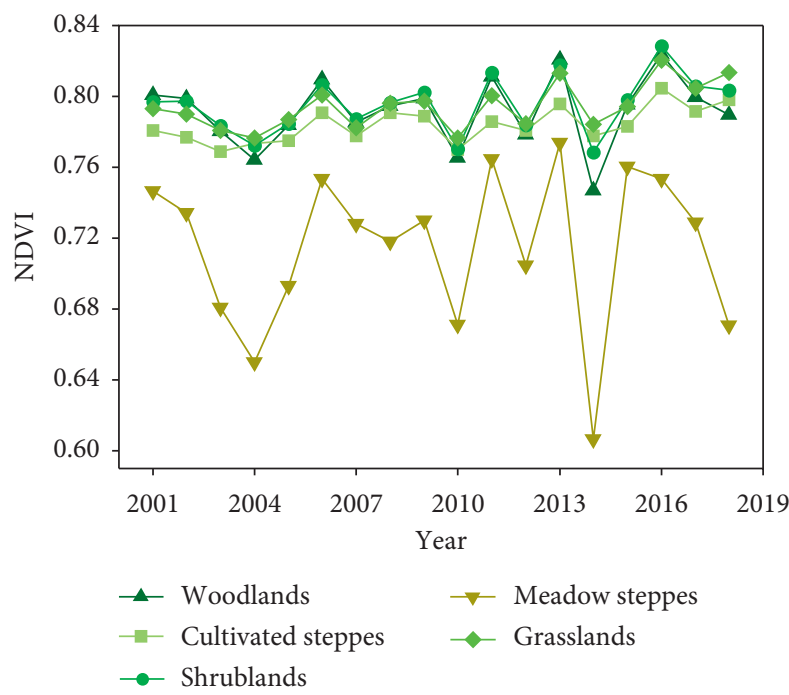

(c)

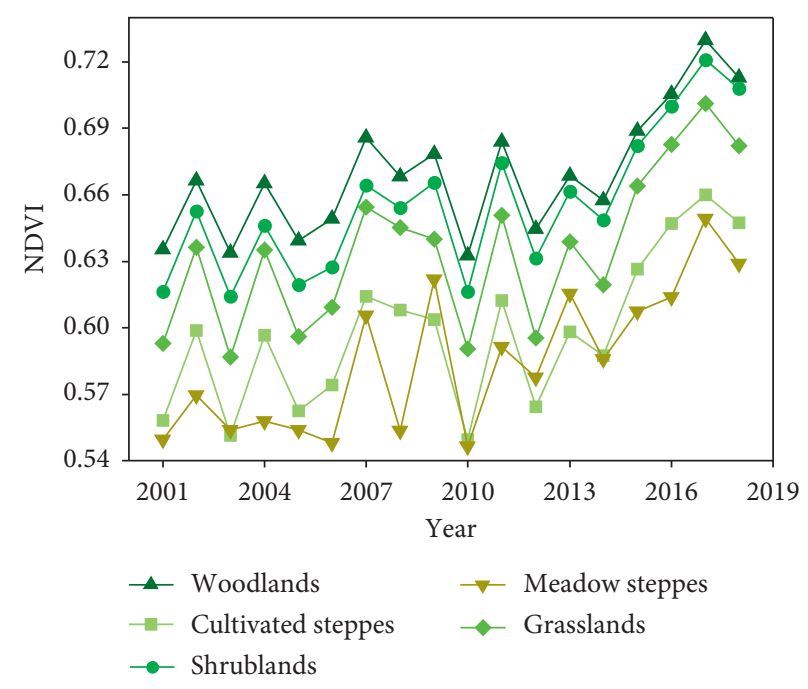

(b)

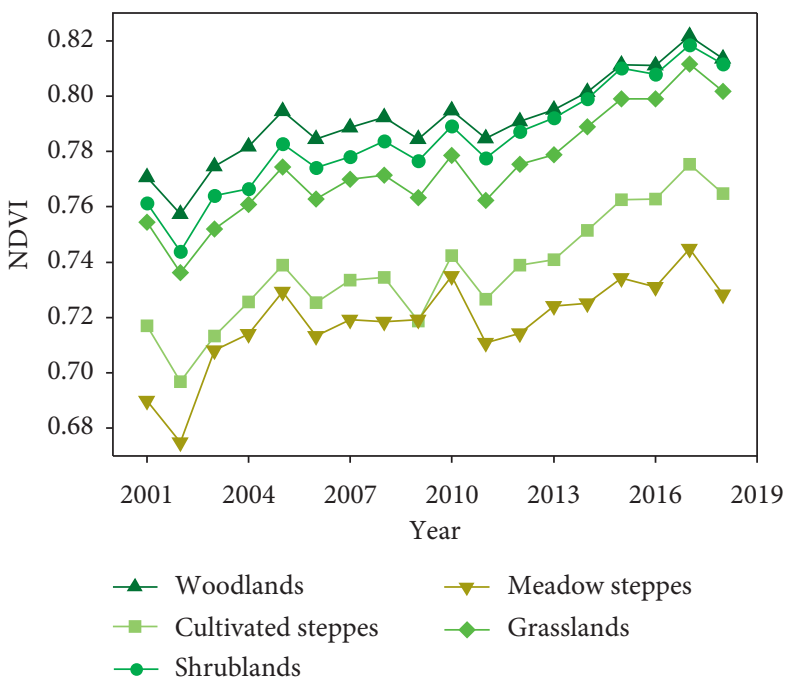

(d)

FIgURE 2: Interannual change of NDVI in different vegetation types in (a) growing season, (b) spring, (c) summer, and (d) autumn.

relationship between NDVI and aspect showed that the high-value areas of NDVI were mainly concentrated in north, northeast, and northwest and that the lowest-value areas of NDVI were mainly distributed in south (Figure 4(c)).

The value of CV increased as altitude increased; the maximum value was obtained when the altitude was greater than $4000 \mathrm{~m}$, and the minimum value was obtained when the altitude was 500-1000 m (Figure 4(c)). However, the relationship between $\mathrm{CV}$ and slope was opposite to that between $\mathrm{CV}$ and altitude. The CV value decreased with the increase of slope, and the maximum value was obtained when the slope was less than $5^{\circ}$ (Figure 4(d)). Furthermore, the regions with the maximum $\mathrm{CV}$ value were distributed in the east, followed by the southeast, south, southwest, west, northwest, northwest, and north (Figure 4(e)).

The proportion of significant and extremely significant increase and significant decrease and extremely significant decrease for NDVI with the increase of altitude decreased (Figure $4(\mathrm{~g})$ ). The proportion of insignificant increase and significant decrease for NDVI with the increase of altitude increased; especially when the altitude was more than $3000 \mathrm{~m}$, the proportion of insignificant decrease of NDVI increased rapidly. The relationship between NDVI trends and slope showed that the proportion of extremely significant decrease and significant decrease of NDVI was decreased with the increase of slope, the proportion of insignificant increase of NDVI remained unchanged, the proportion of insignificant increase of NDVI decreased first and then increased, and the proportion of extremely significant increase and significant increase of NDVI increased first and then decreased (Figure 4(h)). In addition, the relationship between NDVI trends and aspect showed the proportion of significant increase of NDVI, with the maximum proportion occurring in the east and the minimum proportion distributing in the west. Of the proportion of 

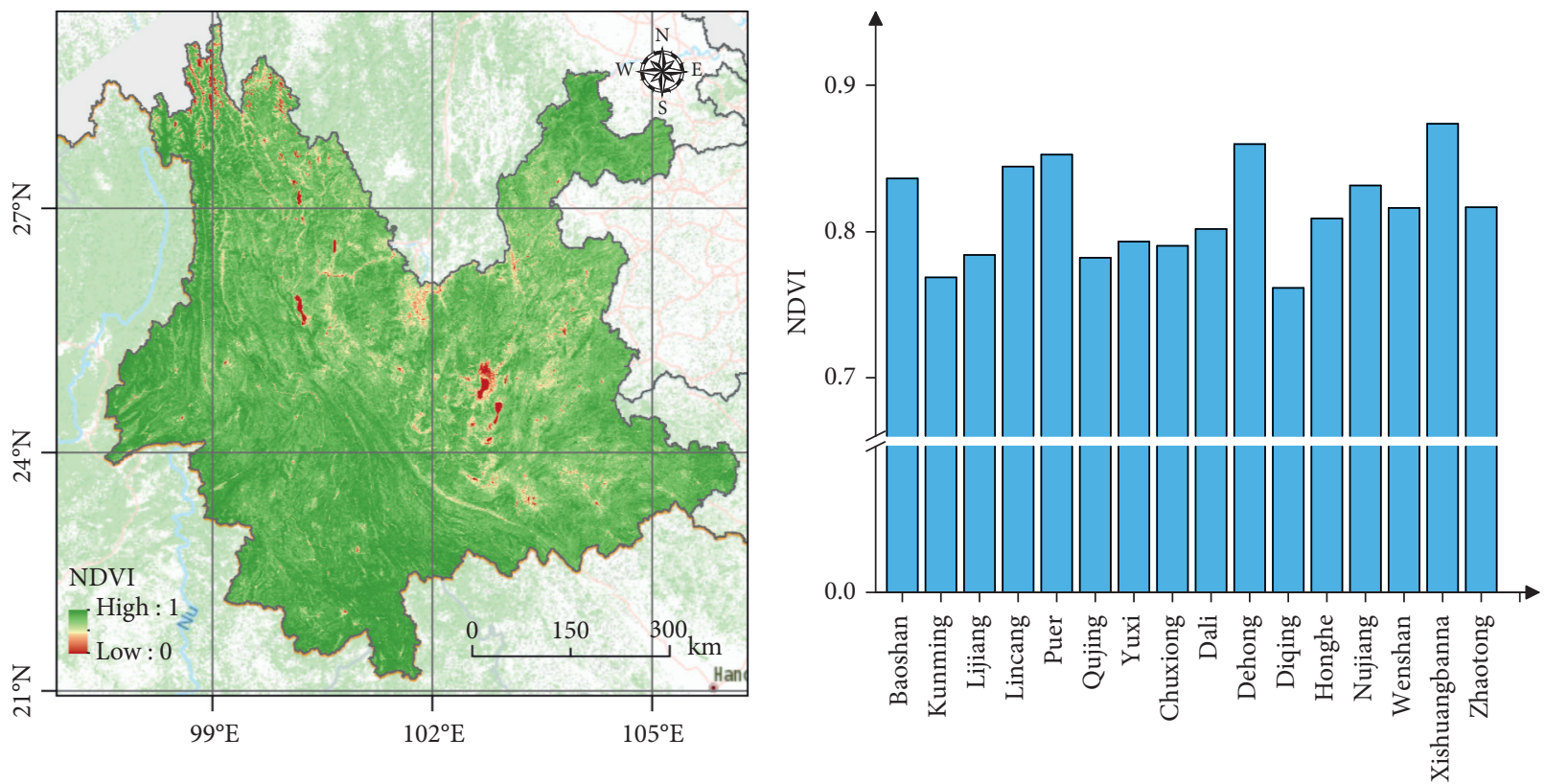

City

(a)

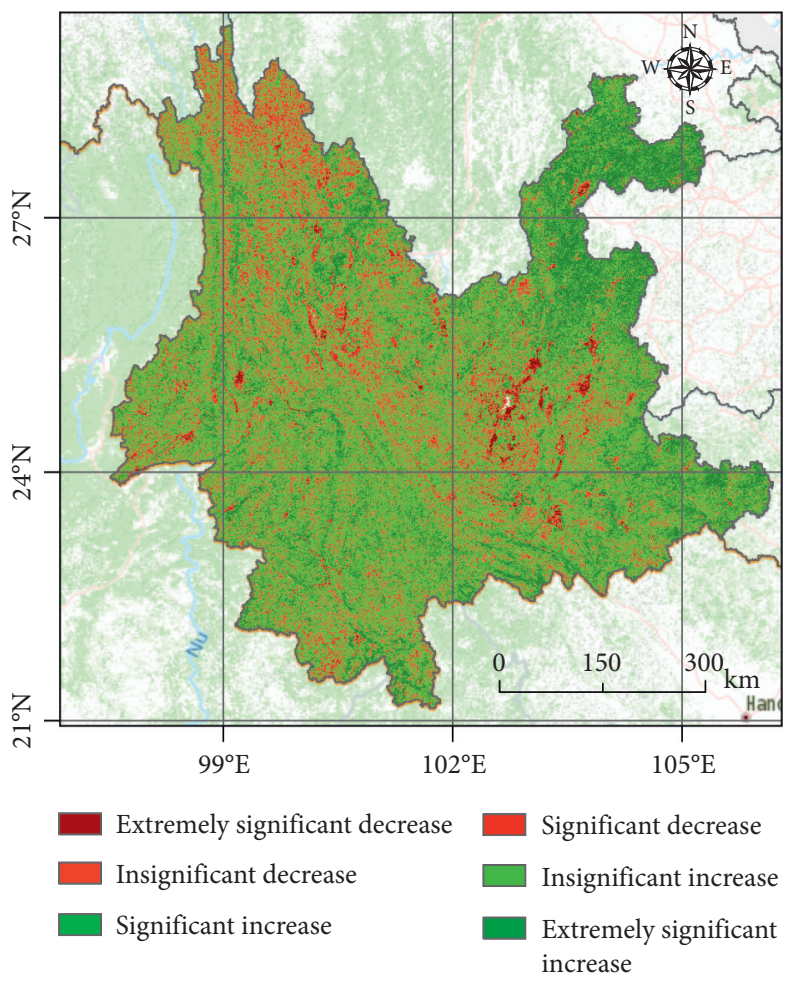

(b)

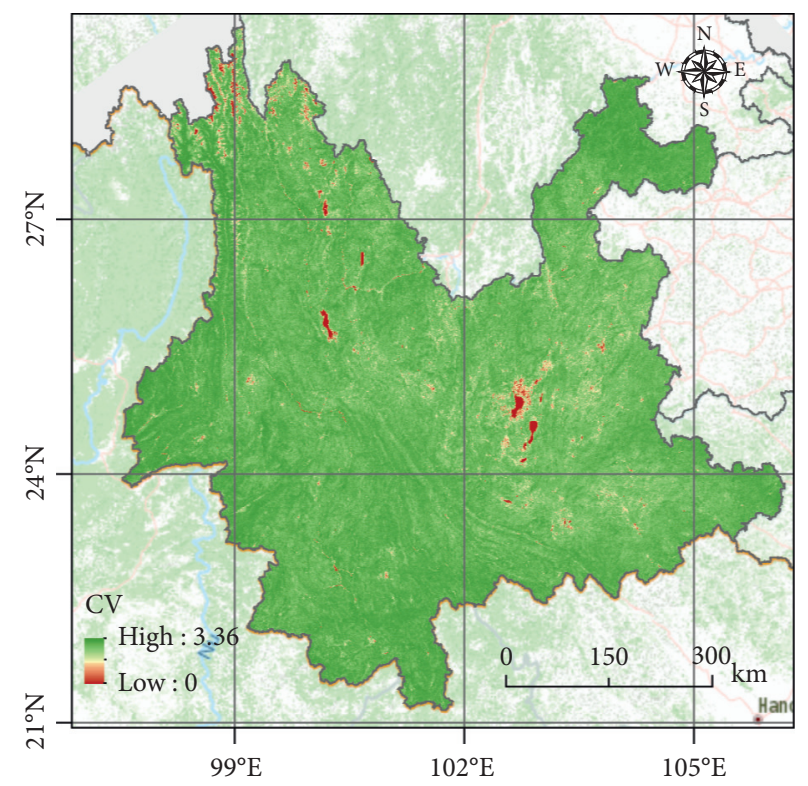

(c)

(d)

Figure 3: The characteristic spatial patterns of NDVI. (a) Spatial distribution of NDVI of Yunnan Province from 2001 to 2018; (b) characteristics of NDVI in different cities; (c) trends of the NDVI based on the M-K significance test across the Yunnan Province during 2001-2018; (d) stability of NDVI change across the Yunnan Province over 2001-2018. 
TABLE 3: Statistics of NDVI trends in the Yunnan Province from 2001 to 2018.

\begin{tabular}{lcc}
\hline Status & Area $\left(\mathrm{km}^{2}\right)$ & Proportion (\%) \\
\hline Extremely significant decrease & 3763.47 & 0.98 \\
Significant decrease & 5034.68 & 1.31 \\
Insignificant decrease & 65137.21 & 16.95 \\
Insignificant increase & 188188.81 & 48.97 \\
Significant increase & 60740.26 & 15.81 \\
Extremely significant increase & 61409.48 & 15.98 \\
\hline
\end{tabular}

extremely significant increase, the significant increase of NDVI with the maximum proportion occurred in the northwest and the minimum proportion mainly distributed in the east. Finally, the relationship between the insignificant decrease of NDVI and aspect and the insignificant increase of NDVI and aspect is consistent (Figure 4(i)).

\subsection{Spatiotemporal Patterns of Climate Factors}

3.2.1. Temporal Pattern of Climate Factors. Figure 5 shows the interannual variation of precipitation and air temperature in different seasons in Yunnan Province from 2001 to 2018. For the entire observation period, the growing season and spring precipitation showed an insignificant downward trend, with a decreased rate of $1.89 \mathrm{~mm} /$ year and $3.3 \mathrm{~mm} /$ year, respectively (Figures 5(a) and 5(b)). However, summer and autumn precipitation had an insignificant increased trend, with an increased rate of $1.44 \mathrm{~mm} /$ year and $0.42 \mathrm{~mm} /$ year, respectively (Figures 5(c) and 5(d)). Compared with the precipitation, air temperature experienced an increased trend in different seasons. The increased rate of air temperature was largest in autumn $\left(0.04^{\circ} \mathrm{C} /\right.$ year, $R^{2}=0.27$, $P>0.01$, Figure $5(\mathrm{~d}))$ followed by the growing season $\left(0.03^{\circ} \mathrm{C} /\right.$ year, $R^{2}=0.22, P<0.05$, Figure $\left.5(\mathrm{a})\right)$, spring $\left(0.03^{\circ} \mathrm{C} /\right.$ year, $R^{2}=0.09, P>0.01$, Figure $\left.5(\mathrm{~b})\right)$, and summer $\left(0.03^{\circ} \mathrm{C} /\right.$ year, $R^{2}=0.27, P<0.05$, Figure $\left.5(\mathrm{c})\right)$.

3.2.2. Spatial Pattern of Climate Factors. In this study, we adopted the precipitation and air temperature to reflect the impacts of climate factors on vegetation. As displayed in Figures 6 and 7, the precipitation demonstrates a descending gradient from southwest toward northeast in different seasons, and the spatial distribution of precipitation is extremely uneven. The areas with high values of precipitation were mainly concentrated in Xishuangbanna, Puer, Lincang, Baoshan, and Dehong. Low values of precipitation areas were mainly distributed in Diqing, Chuxiong, Kunming, Yuxi, and Zhaotong. It is different from the spatial distribution of precipitation, and the air temperature decreased from the middle of the study area to the periphery, with the low values mainly in Diqing, Lijiang, Nujiang, and Qujing, and the high values mainly in Chuxiong, Kunming, Yuxi, and Xishuangbanna.

\subsection{Relationships between Climate Variables and Vegetation} for Different Seasons. Figure 8 shows the correlations between the NDVI and precipitation in different seasons in Yunnan Province. We found that the relationships between growing season NDVI and growing season precipitation showed mainly insignificant positive correlations (accounting for more than 45\%), followed by insignificant negative correlations (accounting for more than 40\%) and significant positive correlations (accounting for about 5\%, Figure $8(\mathrm{a})$ ). The insignificant negative correlation areas were mainly concentrated in northwest, north, and southwest of Yunnan Province. The areas with insignificant positive correlation were mainly distributed in southeast and northeast of Yunnan Province. In addition, some significant positive correlation areas were mainly concentrated in Zhaotong. In spring, the main relationship between NDVI and precipitation included insignificant positive correlations (areas mainly concentrated in northwest and southwest of Yunnan Province), insignificant negative correlations (areas mainly emerged in northeast, southeast, and northwest of Yunnan), and significant positive correlations (areas mainly distributed in Zhaotong, Chuxiong, and Lijiang, Figure 8(b)). In summer, an insignificant positive correlation (mainly in the central and northeast of Yunnan) and insignificant negative correlation (mainly distributed in the northwest of Yunnan) were the main relationships between NDVI and precipitation (Figure 8(c)). In autumn, the main relationships between NDVI and precipitation showed insignificant positive correlations (areas mainly concentrated in southeast and northeast of Yunnan) and insignificant negative correlations (mainly in the northwest of Yunnan), accounting for about $55 \%$ and $30 \%$, respectively (Figure 8(d)).

To reveal the impacts of air temperature on NDVI in different seasons, the correlation coefficient between NDVI and air temperature was calculated at each pixel scale. As shown in Figure 9, in growing season, the main relationship between NDVI and air temperature showed insignificant positive correlations (accounting for about 50\%), which was mainly distributed in north, southeast, and northeast of Yunnan Province (Figure 9(a)). In spring, the main relationship between NDVI and air temperature showed insignificant negative correlations (mainly emerged in the central of Yunnan Province), which accounted for about $50 \%$ (Figure 9(b)). In addition, the areas with insignificant positive correlation also account for a large proportion (about 25\%), which were concentrated in Zhaotong, Nujiang, and some areas of Wenshan. In summer, the relationship between NDVI and air temperature showed mainly insignificant positive correlations and insignificant negative correlations, the proportion of which was basically the same (approximately 40\%), and the distribution of the regions was scattered (Figure 9(c)). In autumn, the main relationship between NDVI and air temperature were insignificant positive correlations, accounting for about $60 \%$ (Figure 9(d)). Furthermore, the relationship between NDVI and air temperature showed insignificant negative correlations and accounted for a large proportion (approximately $25 \%$ ), which mainly emerged in Chuxiong and Dehong.

3.4. Lag Analysis of Vegetation to Climatic Factors for Different Seasons. In order to study the vegetation lag effects to 


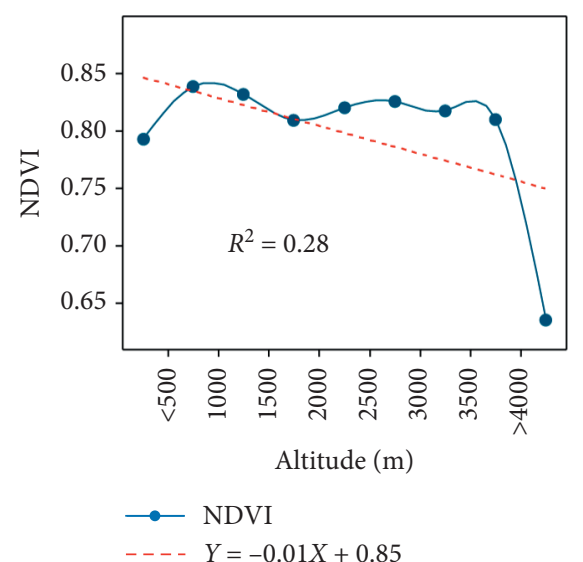

(a)

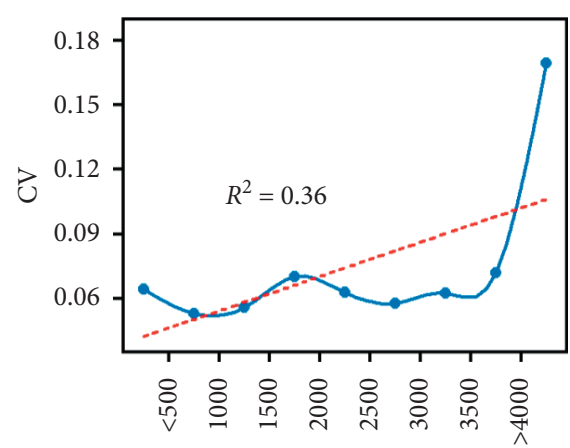

Altitude (m)

$\longrightarrow \mathrm{CV}$

- - $\quad Y=0.008 X+0.04$

(d)

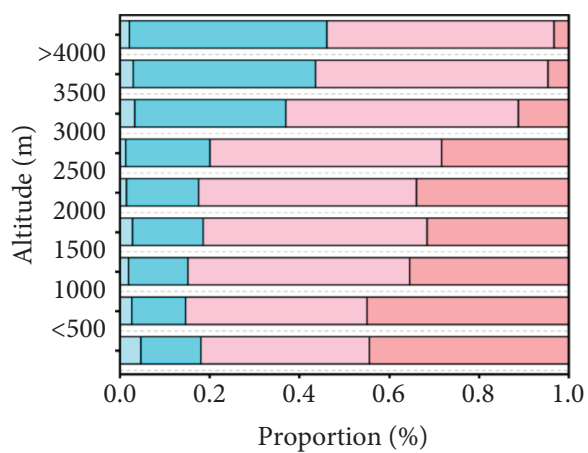

$\square$ Significant increase and extremely significant increase

$\square$ Insignificant increase

$\square$ Significant decrease and extremely significant decrease

$\square$ Insignificant decrease

(g)

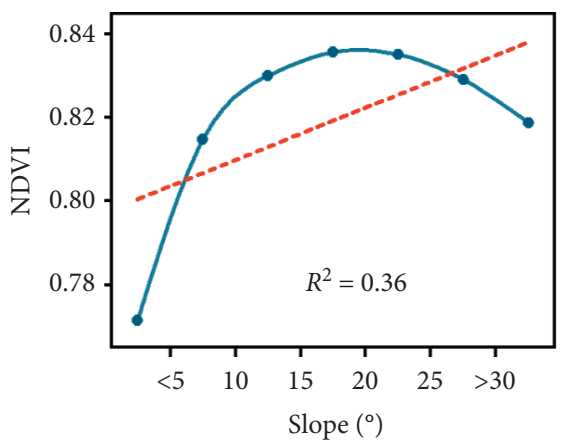

$\because$ NDVI

$---\quad Y=0.006 X+0.80$

(b)

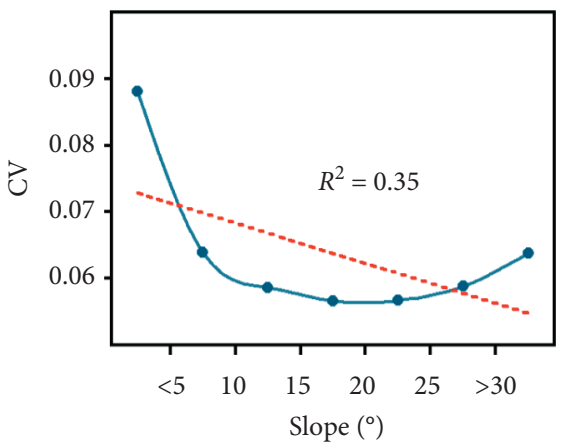

$\longrightarrow \mathrm{CV}$

$---Y=-0.003 X+0.07$

(e)

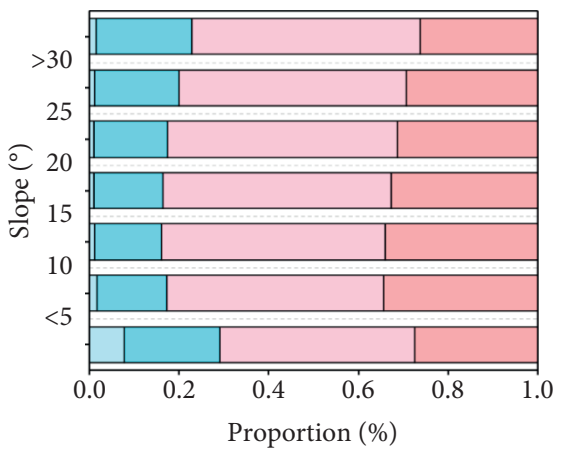

Significant increase and extremely significant increase

$\square$ Insignificant increase

$\square$ Significant decrease and extremely significant decrease

$\square$ Insignificant decrease

(h)

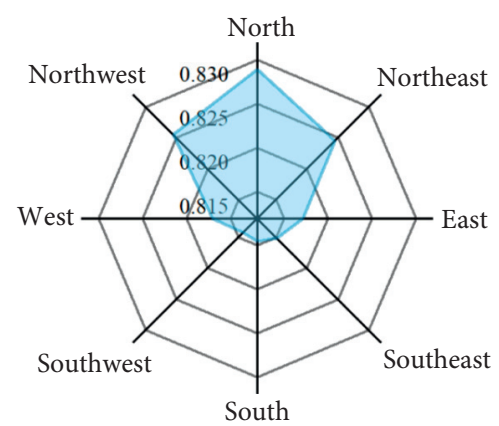

NDVI

(c)

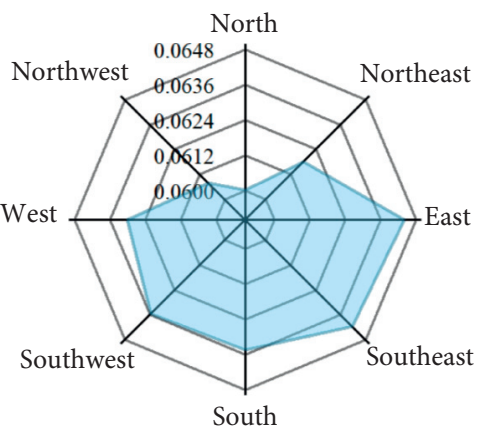

NDVI

(f)

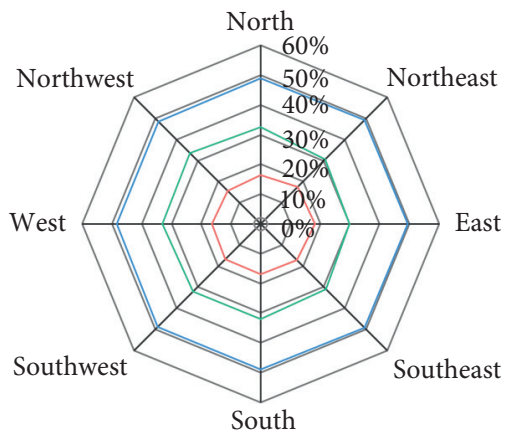

- Significant decrease and extremely significant decrease

_ Insignificant decrease

__ Insignificant increase

Significant increase and extremely significant increase

(i)

FIGURE 4: The relationship between different terrain factors and NDVI, CV, and NDVI trends. (a-c) Distribution and change characteristics of NDVI at different altitudes, slopes, and aspects, respectively; (d-f) distribution and change characteristics of CV at different altitudes, slopes, and aspects, respectively; (g-i) distribution and change characteristics of NDVI trends at different altitudes, slopes, and aspects, respectively. 


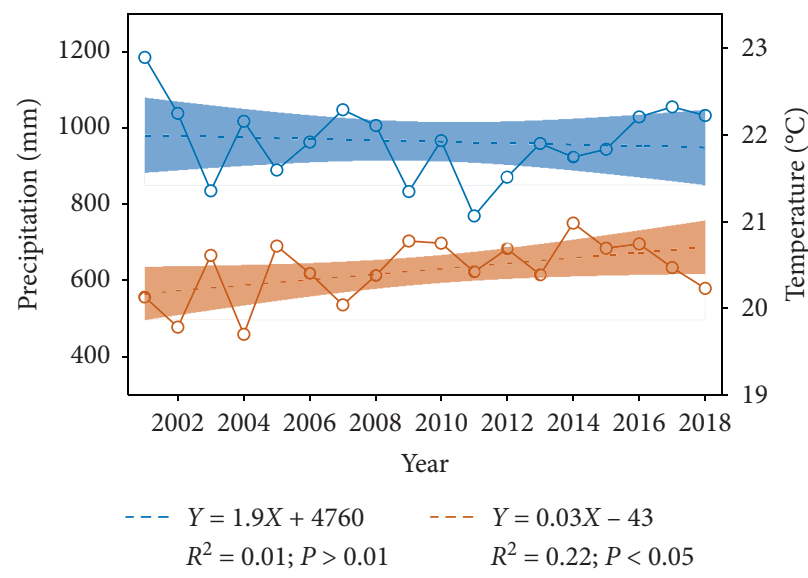

(a)

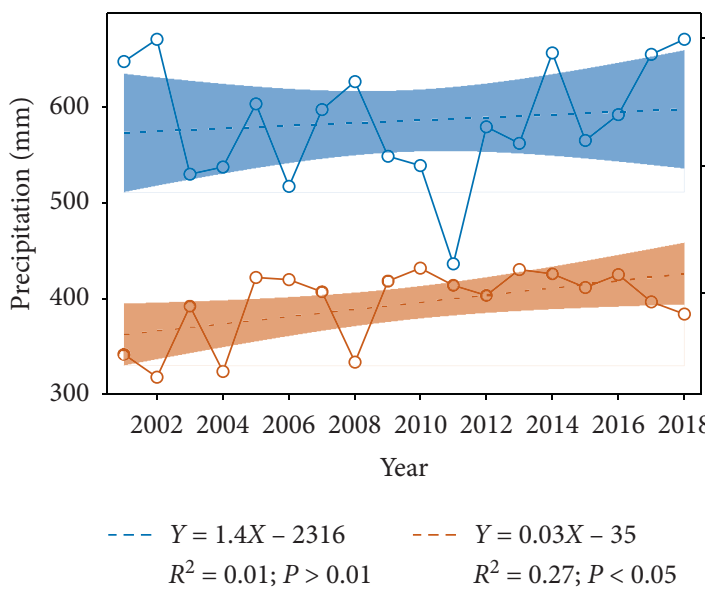

(c)

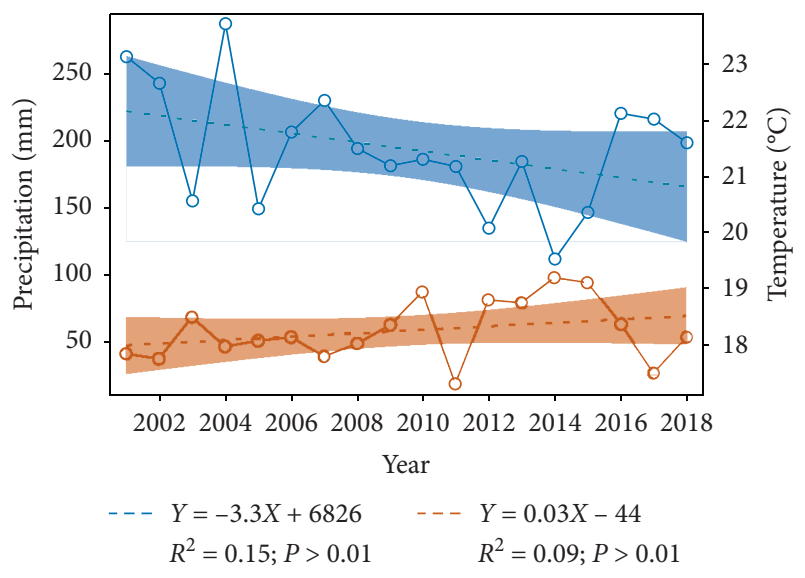

(b)

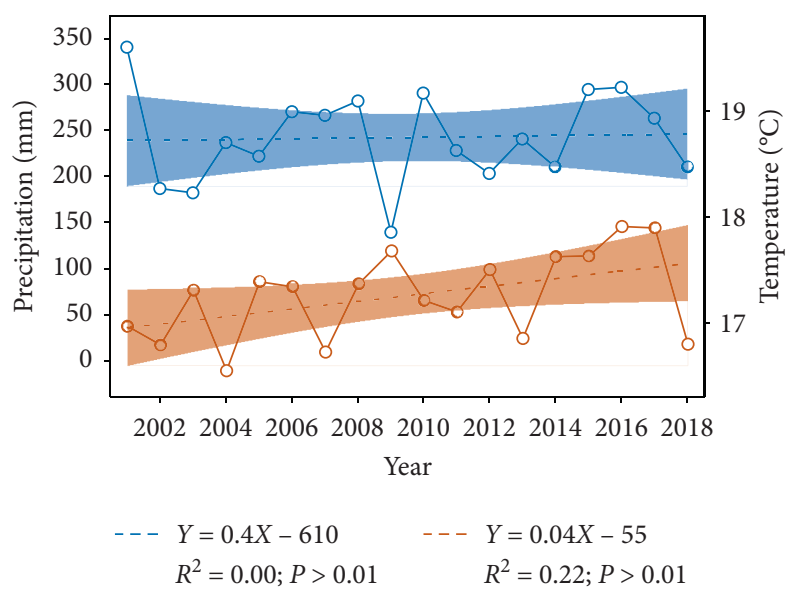

(d)

FIGURE 5: Interannual variation of precipitation and temperature. (a) Growing season; (b) spring; (c) summer; (d) autumn. The blue dotted line is the fitting line and the blue solid line is the variation line of the precipitation. The brown dotted line is the fitting line and the brown solid line is the variation line of the temperature.

climate change for different seasons, we analyzed the correlation between precipitation, air temperature, and NDVI in different seasons. As shown in Figure 10, the relationship between spring precipitation and summer NDVI showed mainly insignificant positive correlations (approximately $50 \%$ ), which was mainly distributed in the central and northeast of Yunnan Province (Figure 10(a)). On the contrary, the main relationship between spring precipitation and autumn NDVI showed insignificant negative correlations (nearly distributed in the whole region of Yunnan), which accounted for about 55\% (Figure 10(b)). In addition, the relationship between summer precipitation and autumn NDVI showed mainly insignificant positive correlations (accounting for about 50\%), which was distributed in the southwest and northeast of Yunnan Province (Figure 10(c)). Compared with the relationship between NDVI and precipitation, areas with positive correlations between NDVI and air temperature in different seasons increased insignificantly. The insignificant positive correlations (mainly distributed in the central and northwest of Yunnan) and insignificant negative correlations (mainly in northeast of Yunnan) were the main relationships between spring air temperature and summer NDVI, the proportion of which was basically the same (accounting for about 40\%, Figure $10(\mathrm{~d})$ ). The relationship between spring temperature and autumn NDVI showed that the proportion with insignificant positive correlation and negative correlation was the highest, which emerged mainly in the northwest and southeast of Yunnan Province and the central and southwest of Yunnan, respectively (Figure 10(e)). Furthermore, the relationship between summer air temperature and NDVI showed mainly insignificant positive correlations, and the proportion was more than 50\%, and it was mainly distributed in the northwest and southeast of Yunnan Province (Figure 10(f)).

We further examined the concurrent and lagged effects of precipitation and air temperature on NDVI. The inhibition effects of spring precipitation on summer NDVI and autumn NDIV increased gradually (more and more regions with a correlation coefficient less than 0 ); in particular, the spring precipitation had the most obvious inhibition effects on autumn NDVI (Figures 11(a) and 11(b)). On the contrary, there were significant differences in the effects of summer precipitation on summer NDVI and autumn 


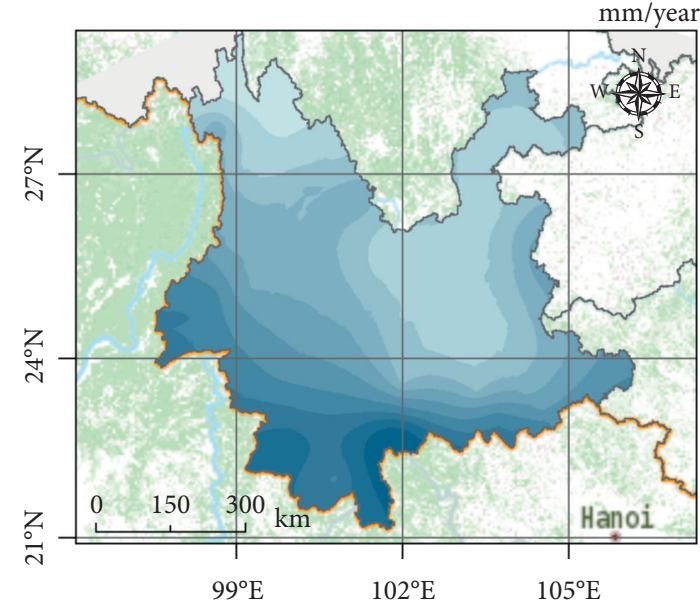

(a)

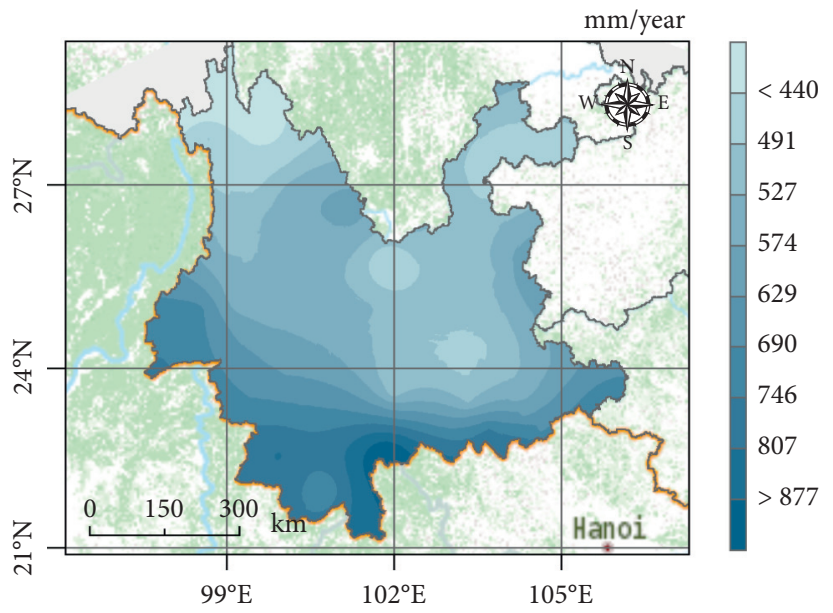

(c)

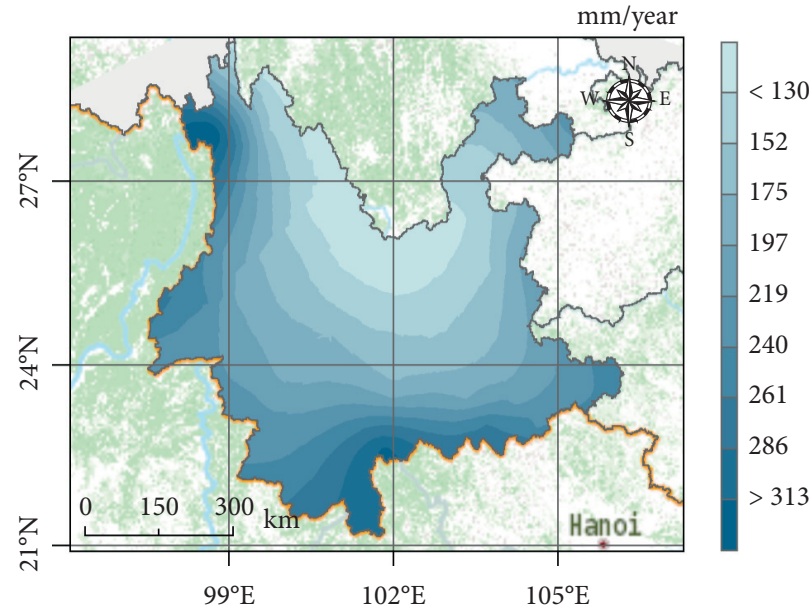

(b)

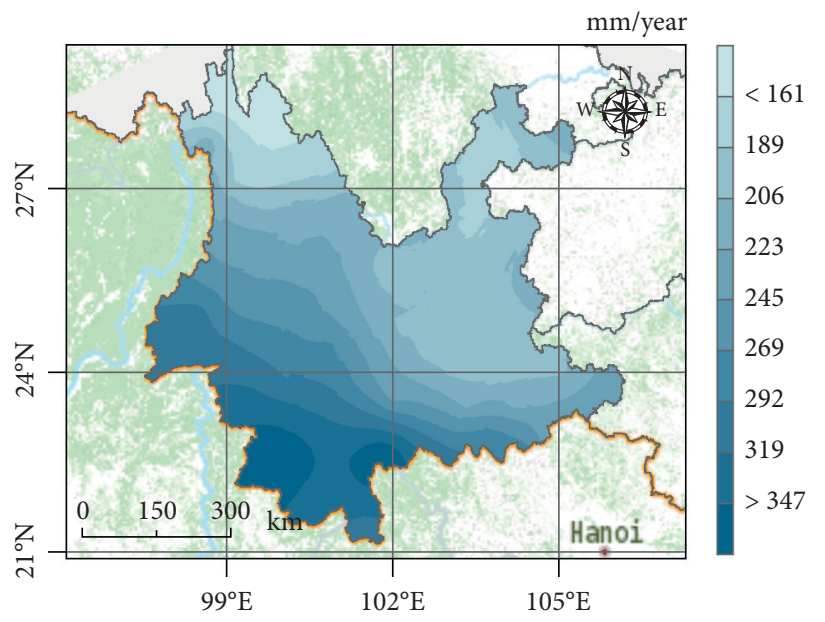

(d)

Figure 6: Spatial pattern of multiyear mean precipitation in (a) growing season; (b) spring; (c) summer; (d) autumn.

NDVI. The relationships between summer precipitation and autumn NDVI showed mainly positive correlations in many regions (Figure 11(c)). Compared with the lag response of NDVI to precipitation, the results showed that the spring air temperature on the summer NDVI, the spring air temperature on the autumn NDVI, and the summer air temperature on the autumn NDVI had a clear facilitated effect (more and more regions with correlation coefficients greater than 0 ), especially for the impacts of spring air temperature to autumn NDVI (Figures 11(d)-11(f)).

\subsection{Lagged Time Response of Monthly NDVI to Climate} Change. Figure 12 displays the correlation coefficients between climatic variables and monthly NDVI in all previous months from 2001 to 2018. The strength of the lag effect and lag period of climate varied with months. Specifically, the correlation coefficient between NDVI and precipitation from April to June is much greater than that of previous months, which represents that the strength of the lag effect of precipitation on vegetation was much less than that with no time lag from April to June. However, the analysis found that in July $(r=0.360 * *, \quad P<0.05)$, August $(r=0.485 * *$, $P<0.05)$, September $(r=0.571 * *, P<0.05)$, and October $(r=0.593 * *, P<0.05)$, there is a significant positive correlation between NDVI and precipitation of the previous month (Figure 11(a)), which indicated that vegetation has a lag period of 1-2 months for precipitation from July to October. Furthermore, for temperature, there is a significant positive correlation between the NDVI in June $(r=0.214 * *$, $P<0.01)$ and August $(r=0.456 * *, P<0.01)$, which represents that there is a monthly lag effect of temperature on NDVI in the summer.

\section{Discussion}

4.1. NDVI Spatiotemporal Patterns. The interannual variation of NDVI in different vegetation types experienced a significant uptrend in the growing season, spring, and autumn (Figure 2). A similar pattern has also been reported in the Tibetan Plateau [32], Amur-Heilongjiang River Basin [6], and Nansi Lake [33]. This phenomenon is inseparable from the impact of anthropogenic factors and climate change. Since the 1980s, Yunnan Province has implemented 


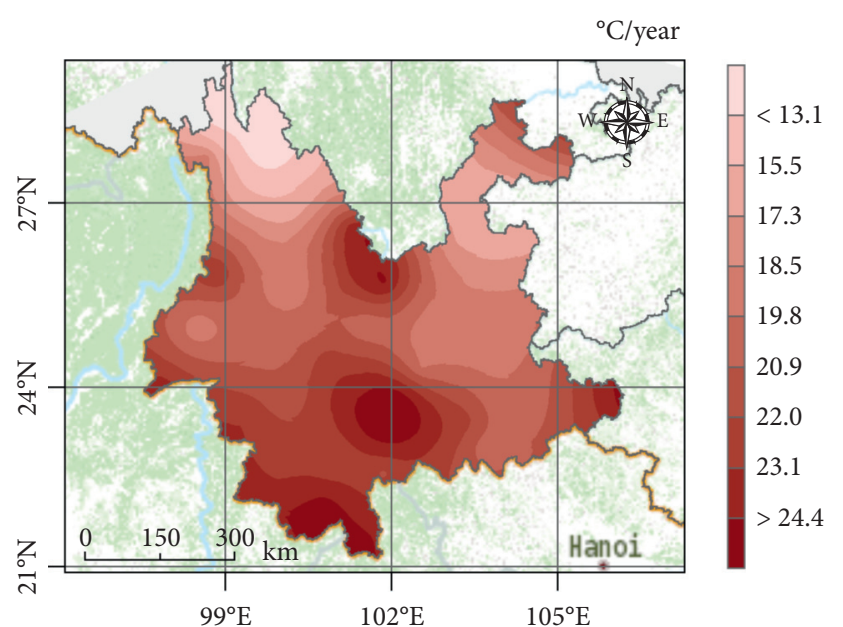

(a)

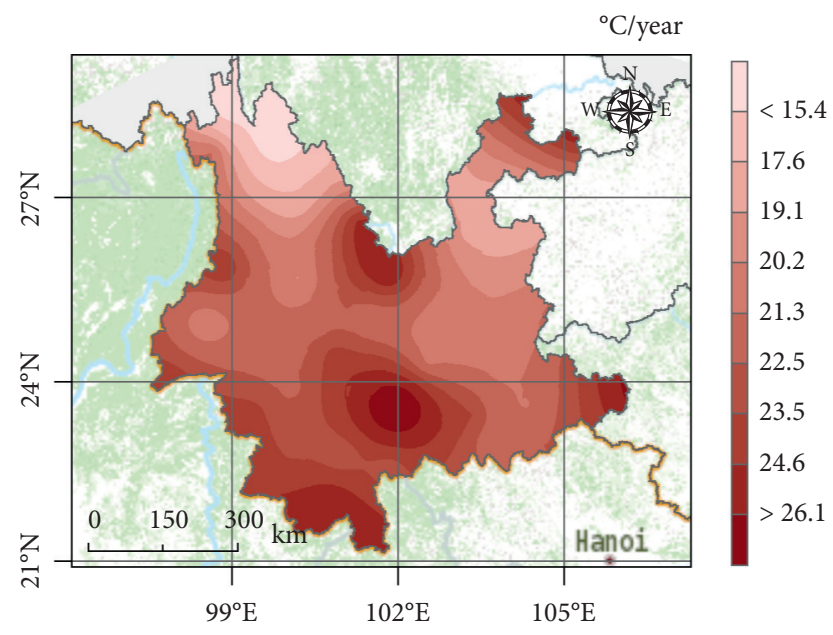

(c)

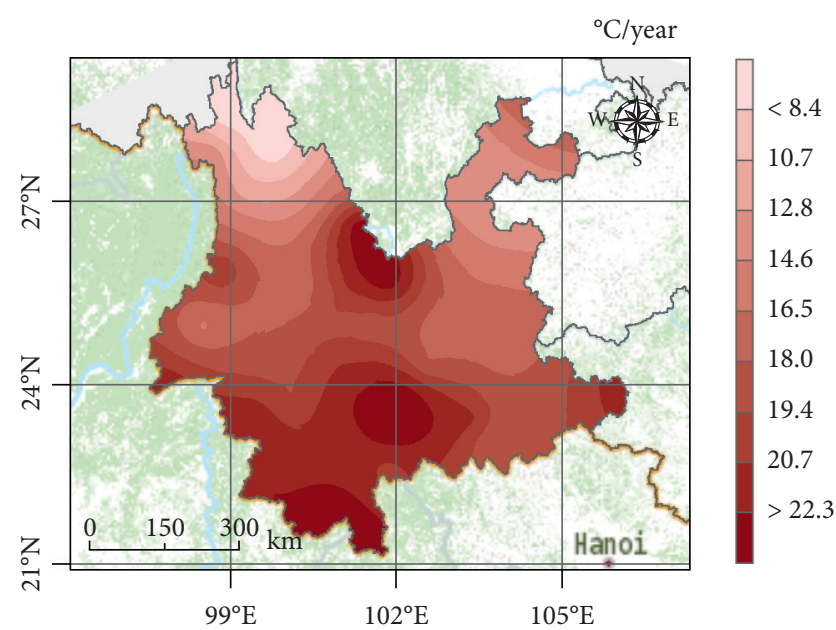

(b)

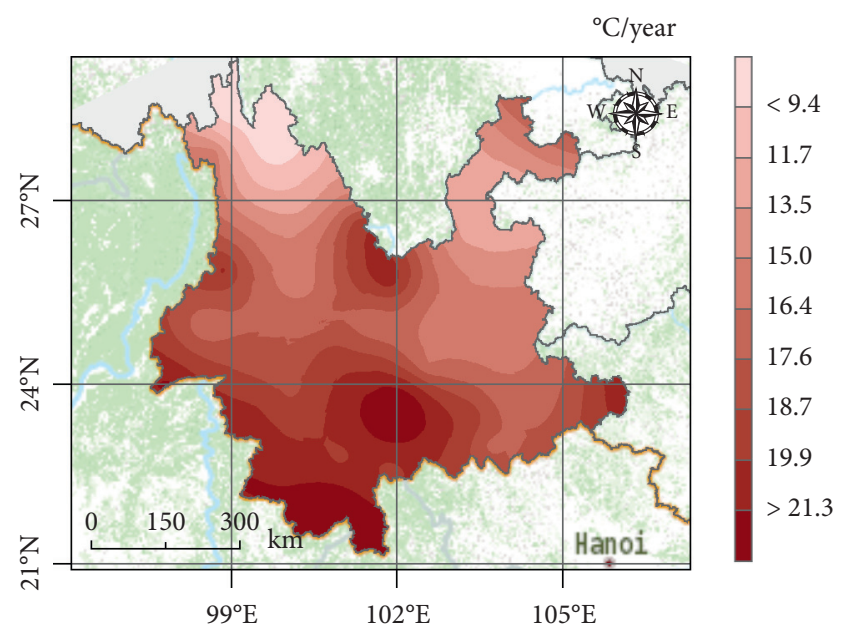

(d)

FIGURE 7: Spatial pattern of multiyear mean temperature in (a) growing season; (b) spring; (c) summer; (d) autumn.

a series of ecological projects, such as the closing of a mountain to decrease afforestation, returning farmland to forest, and artificial afforestation [34, 35]. Yunnan Province has successively formulated and implemented a series of environmental protection laws and regulations, for example, the forest protection project in the upper reaches of the Pearl River and the forest protection project in the upper reaches of the Yangtze River [36]. A previous study has shown that the total area of returning farmland to forest in Yunnan Province from 2001 to 2017 was $6754 \mathrm{~km}^{2}$ [37]. In terms of climate, the precipitation and air temperature in growing season and autumn in Yunnan Province have increased in the past 18 years (Figures 5(a) and 5(d)). The favorable water and heat environment provided important resources for the vegetation growth [38-40]. Sufficient soil moisture ensures the normal operation of vegetation photosynthesis when $\mathrm{CO}_{2}$ concentration and light are sufficient [41]. At the same time, sufficient soil moisture guaranteed nutrient transport [41]. Therefore, the increased precipitation played a crucial role in the increase of NDVI. In addition to precipitation, air temperature is another climate factor that affects the growth of vegetation. Temperature increase could facilitate vegetation growth without encountering water limitation [33]. An increase in temperature will stimulate the enzymatic activities of photosynthesis [39]. In addition, the increase in temperature accelerated the mineralization and decomposition of organic matter, which has been shown to promote the absorption of organic matter by vegetation [42, 43]. Furthermore, the increase of air temperature in the growing season and autumn extends the length of the vegetation growing period, resulting in an increased NDVI in the growing season and autumn $[1,44]$. However, the interannual variation of NDVI in different vegetation types is very small in summer (Figure 2(c)). There are two reasons to explain the above phenomenon. Yunnan Province has both arid and semiarid areas. With the impact of the East Asian monsoon, Indian monsoon, and air masses from the Qinghai-Tibet Plateau, summer are times of relative drought $[45,46]$. This environment reduces the photosynthetic rate and carbon uptake capacity of vegetation. Meanwhile, vegetation flourishes best in summer and NDVI reached its peak. Furthermore, there is a frequent occurrence of natural 


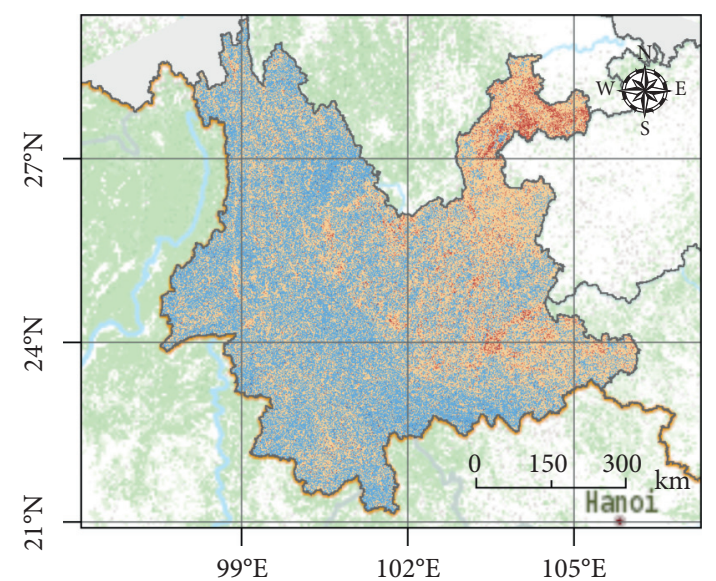

Extremely significant negative correlation

Insignificant negative correlation

Significant positive correlation

Significant negative correlation

Insignificant positive correlation

Extremely significant positive correlation

(a)

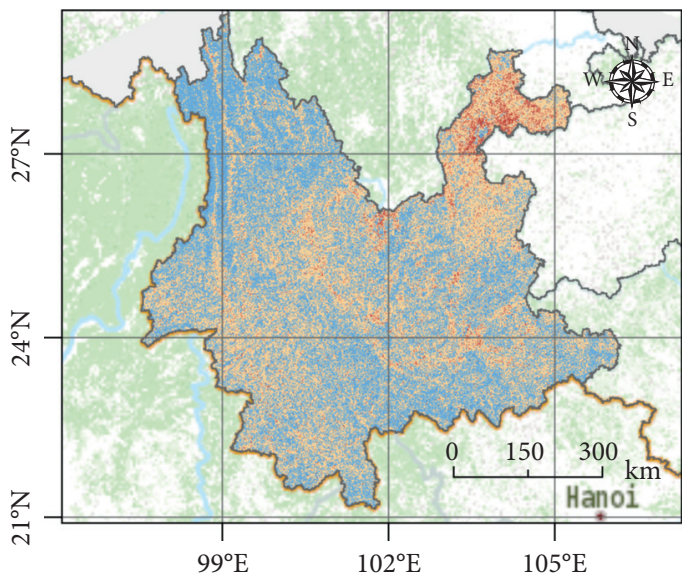

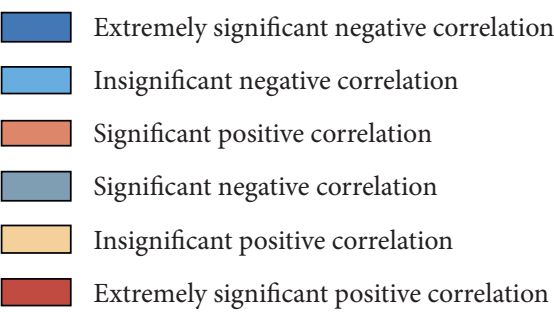

(c)

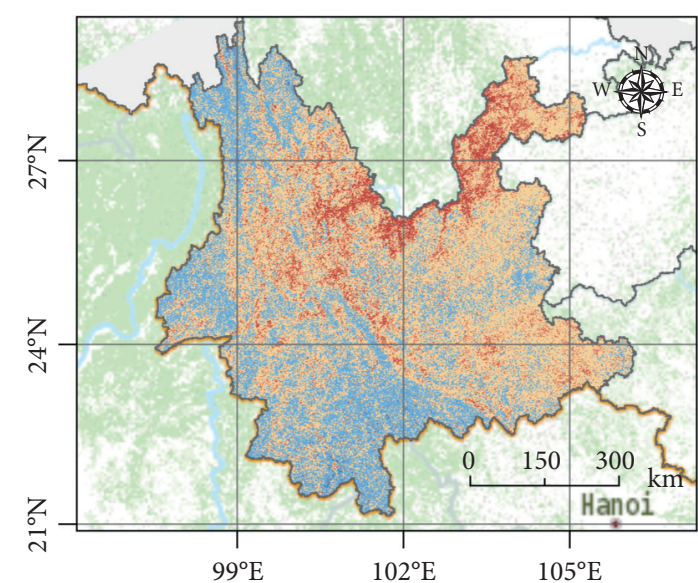

$\square$ Extremely significant negative correlation

$\square$ Insignificant negative correlation

$\square$ Significant positive correlation

$\square$ Significant negative correlation

$\square$ Insignificant positive correlation

$\square$ Extremely significant positive correlation

(b)
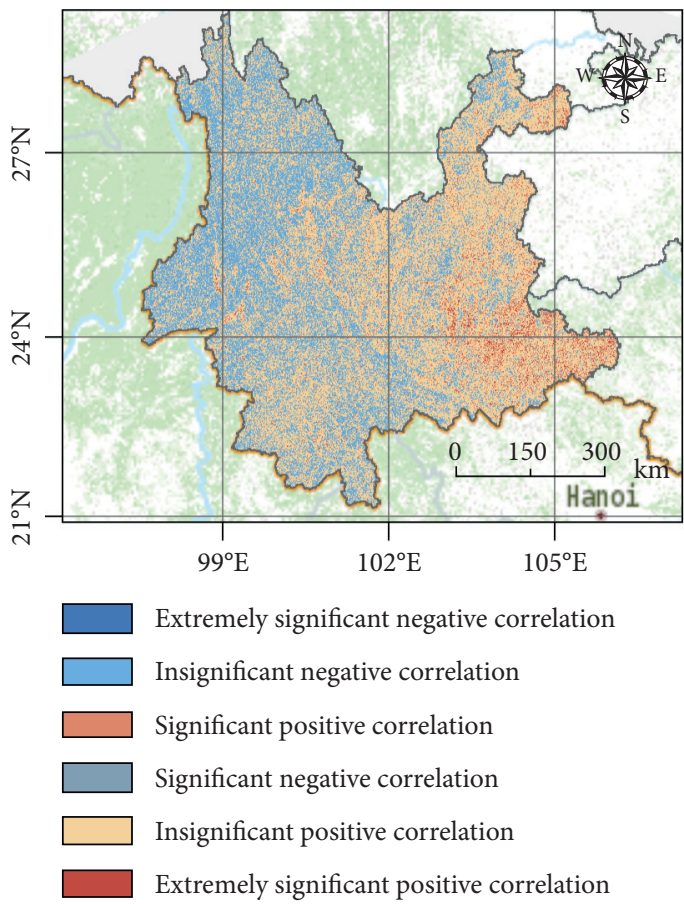

(d)

FIGURE 8: Spatial distributions of correlation coefficients between NDVI and precipitation in different seasons. (a) Growing season; (b) spring; (c) summer; (d) autumn. (a)-(d) represent the proportion of correlation coefficient classification.

disasters (drought, hail, and flash floods) in summer, especially in July [47].

The multiyear (2001-2018) mean NDVI in Yunnan Province has strong spatial heterogeneity, with a distinct gradient variation from northeast to southwest (Figure 3(a)). The primary reasons for this phenomenon are explained as follows: the eastern part of Yunnan Province is hilly and the terrain is relatively flat, but the western part has the Hengduan Mountains, with high mountains and deep valleys, and the altitude difference is large $[16,48]$. This terrain leads to the vegetation types in western Yunnan Province being dominated by woodland; however, the eastern part is 

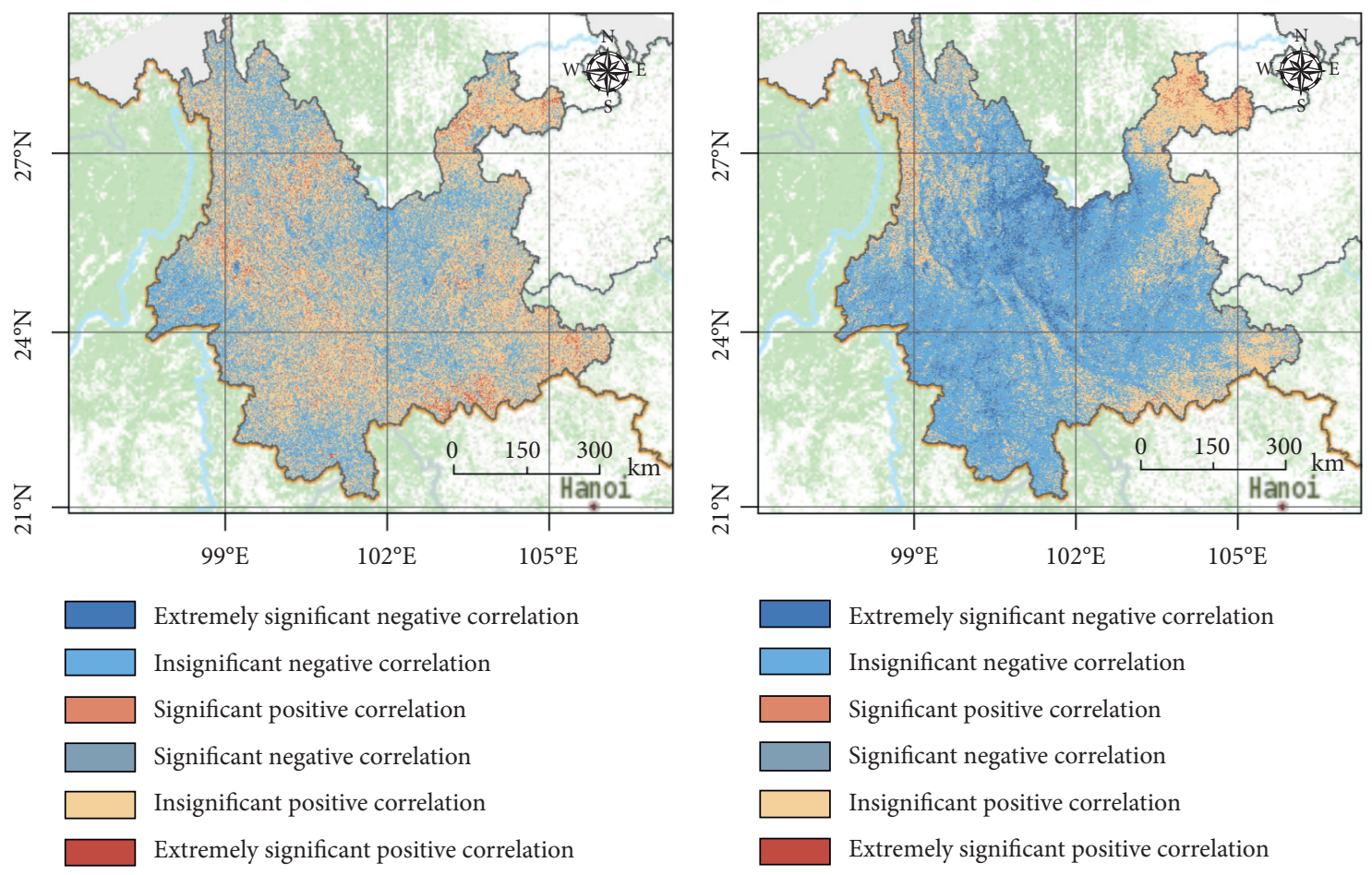

(a)

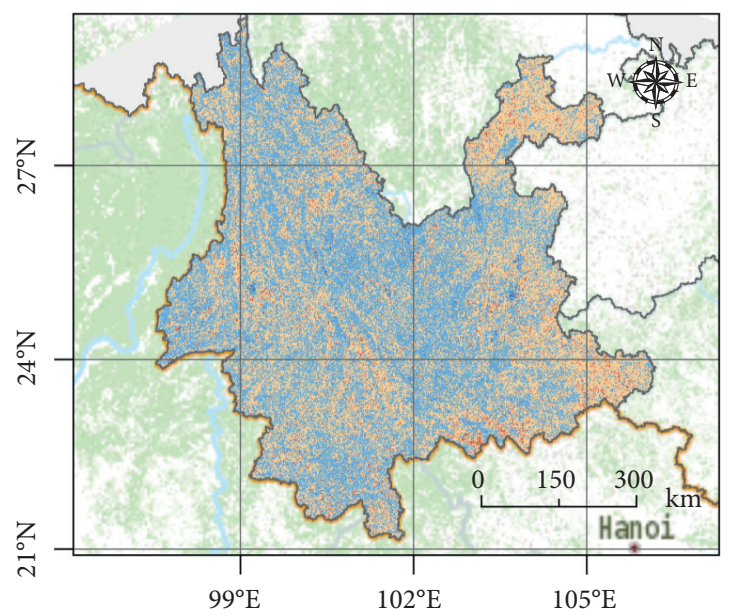

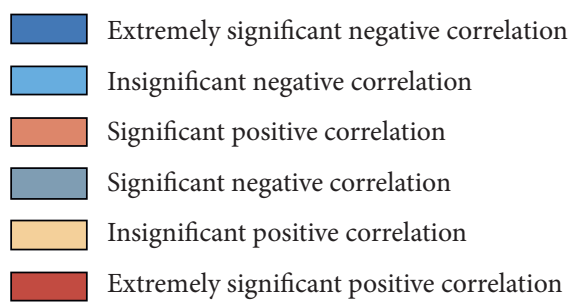

(c)
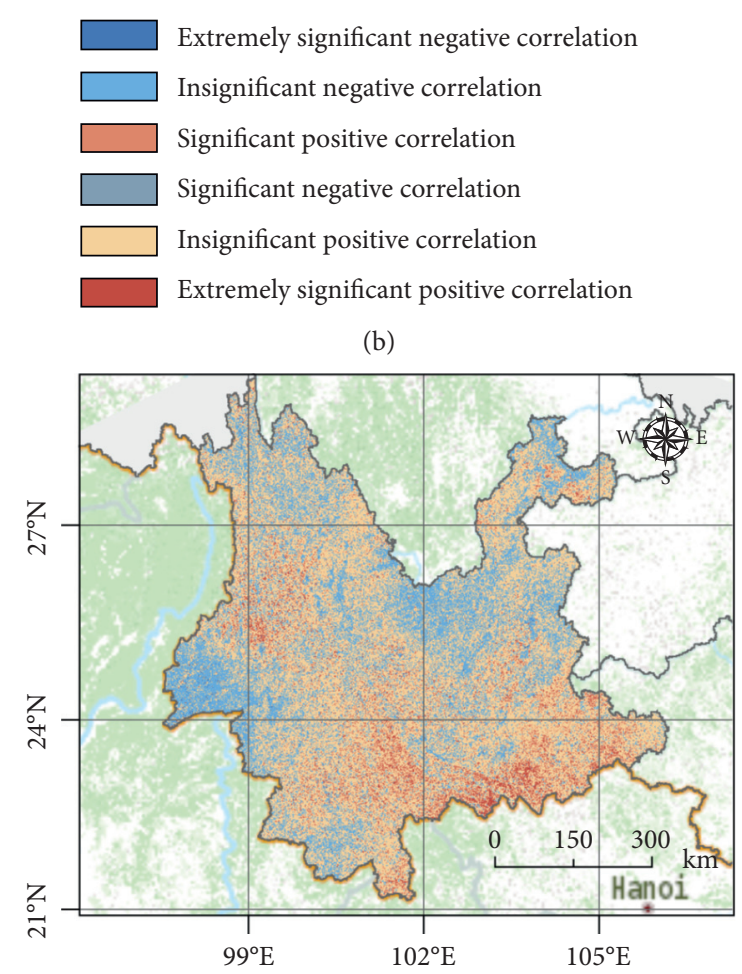

(b)

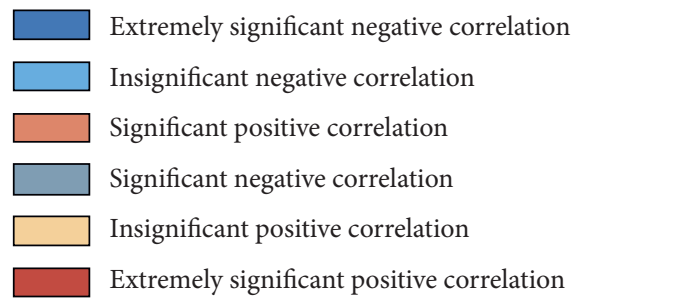

(d)

FIGURE 9: Spatial distributions of correlation coefficients between NDVI and temperature during different seasons. (a) Growing season; (b) spring; (c) summer; (d) autumn. (a)-(d) represent the proportion of correlation coefficient classification.

mainly dominated by cropland and grassland [49], and the economically developed cities of Yunnan Province (such as Kunming, Yuxi, and Qujing) are mainly concentrated in the east. In addition, some areas are covered with snow because of the high altitude of northern Yunnan Province [50].
Meanwhile, we found that the NDVI in central and northern Yunnan Province showed a downward trend, varied wildly, and fluctuated greatly in these areas. Possible reasons include the following: since 1999, with the implementation of the western development strategy, the economy has 


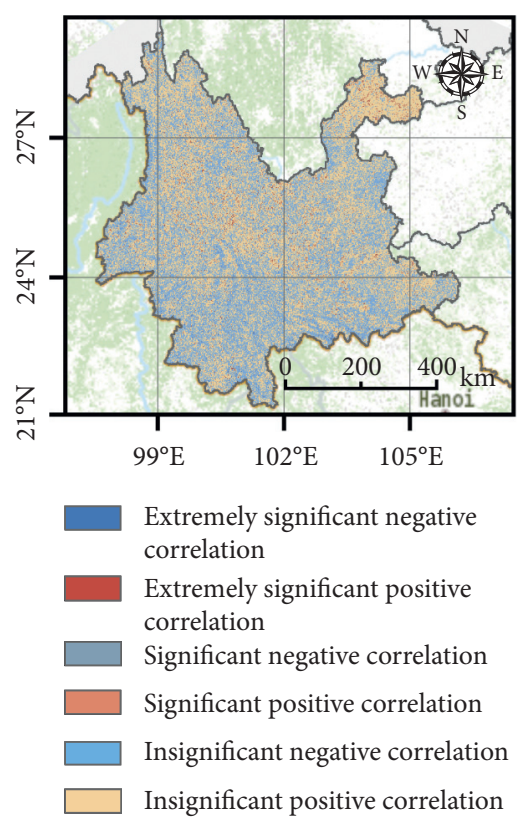

(a)

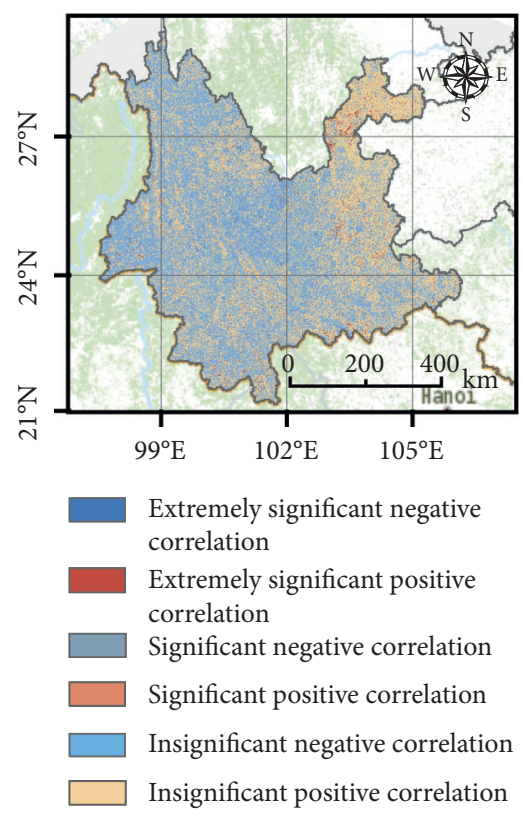

(d)

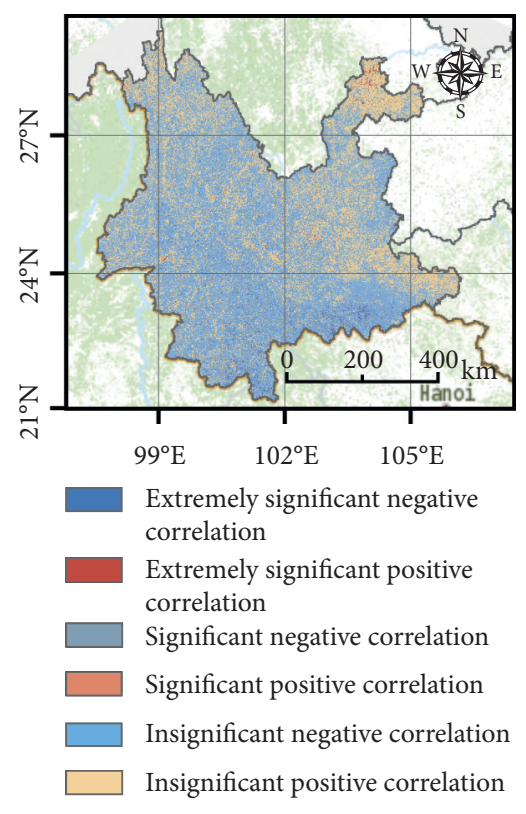

(b)

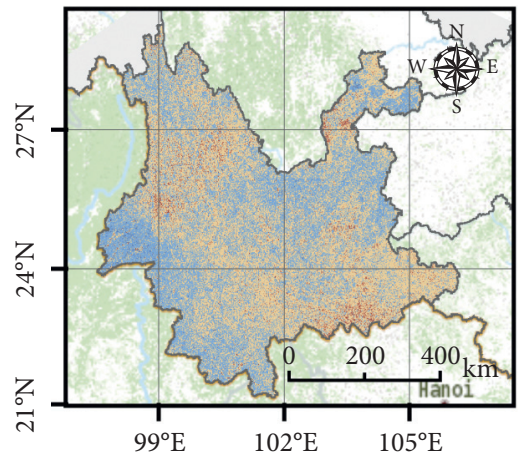

Extremely significant negative correlation

Extremely significant positive correlation

Significant negative correlation

Significant positive correlation

Insignificant negative correlation

Insignificant positive correlation

(e)

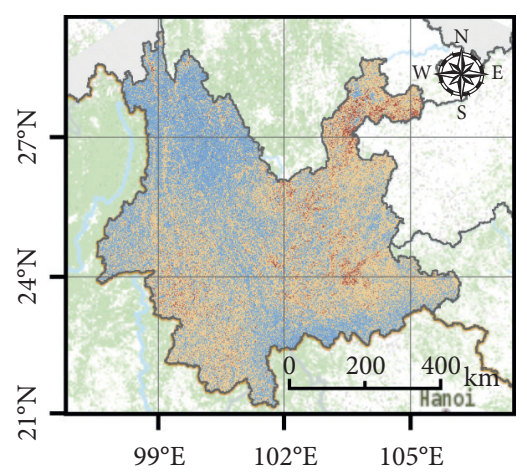

Extremely significant negative correlation

Extremely significant positive correlation

Significant negative correlation

Significant positive correlation

Insignificant negative correlation

Insignificant positive correlation

(c)

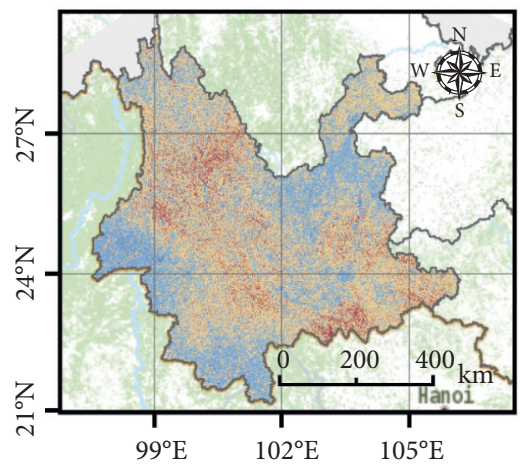

Extremely significant negative correlation

Extremely significant positive correlation

Significant negative correlation

Significant positive correlation

Insignificant negative correlation

Insignificant positive correlation

(f)

FIGURE 10: Spatial distributions of correlation coefficients between NDVI and precipitation or temperature in different seasons. The spatial distribution of correlation coefficients (a) between spring precipitation and summer NDVI; (b) between spring precipitation and autumn NDVI; (c) between summer precipitation and autumn NDVI; (d) between spring temperature and summer NDVI; (e) between spring temperature and autumn NDVI; (f) between summer temperature and autumn NDVI.

developed rapidly, and the impervious surface area of the city (mainly distributed in eastern Yunnan Province) expanded [51]. Another possibility is that the northwest part of Yunnan Province is the southern extension of the Tibet Plateau, which has a higher altitude [52]; this topography makes the ecosystem fragile in this area, and vegetation growth is vulnerable to extreme weather. All these conditions have contributed to make the NDVI in central and northern Yunnan Province decreased over the past 18 years.
Furthermore, the distribution of NDVI is mainly concentrated in the altitude range of 500-4000 m, where slopes are greater than $5^{\circ}$, or shady slopes (northwest, northeast, and north aspect, Figures $4(\mathrm{a})-4(\mathrm{c})$ ). The main reason is that the areas with an altitude less than $500 \mathrm{~m}$ and with a slope less than $5^{\circ}$ are mainly farmland or cities, while the areas with altitude greater than $500 \mathrm{~m}$ and have a slope greater than $5^{\circ}$ are mainly grassland or forest [53]. Meanwhile, the shady slopes have soft solar radiation, moist soil, less moisture 


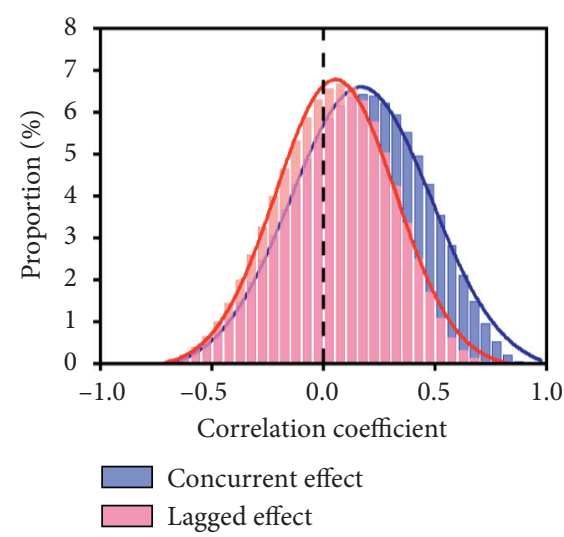

(a)

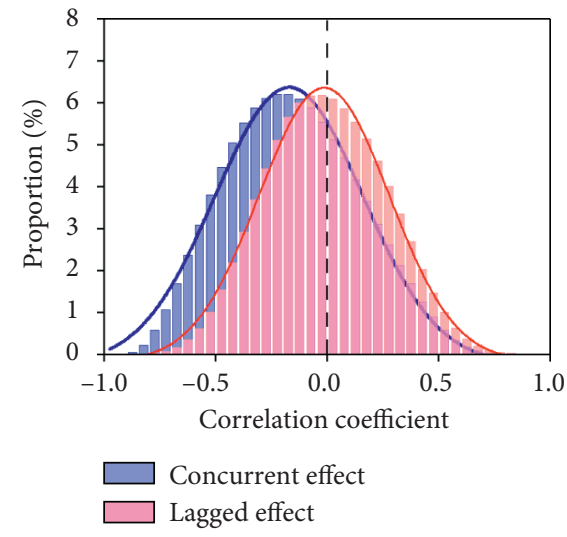

(d)

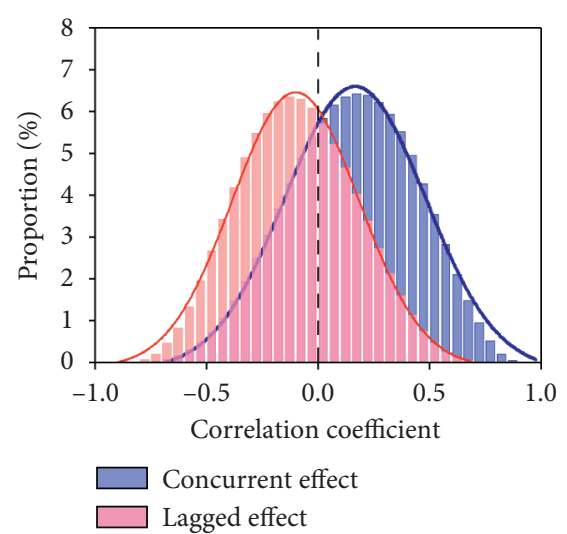

(b)

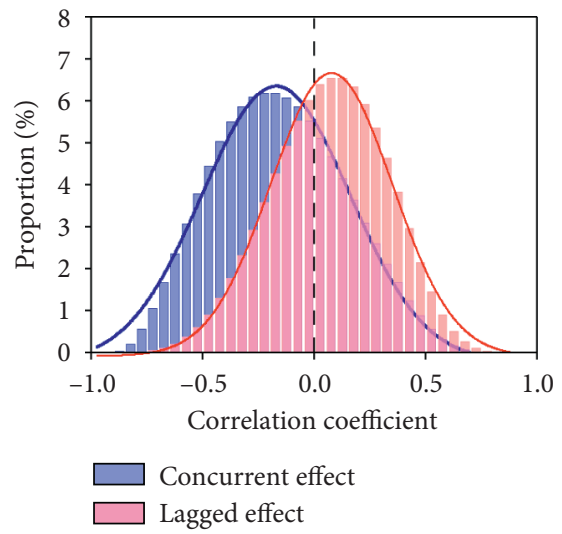

(e)

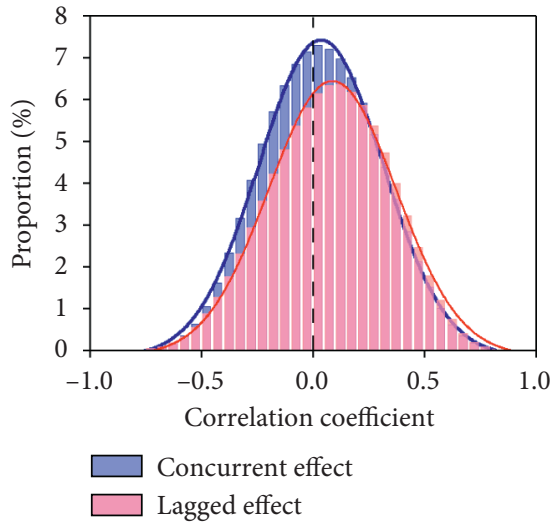

(c)

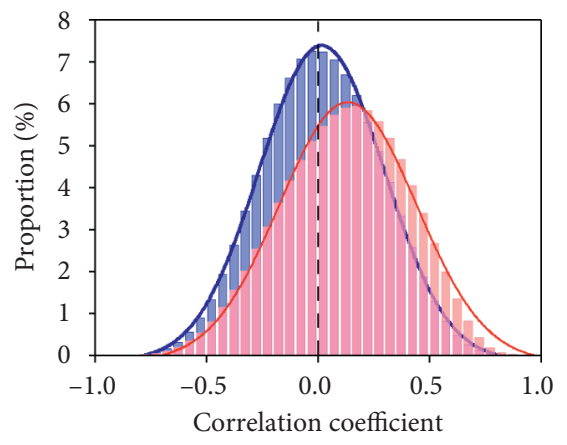

Concurrent effect

Lagged effect

(f)

FIGURE 11: The lag response of NDVI to precipitation and air temperature in different seasons. (a) The lag effect of spring precipitation on summer NDVI; (b) the lag effect of spring precipitation on autumn NDVI; (c) the lag effect of summer precipitation on autumn NDVI; (d) the lag effect of spring air temperature on summer NDVI; (e) the lag effect of spring air temperature on autumn NDVI; (f) the lag effect of summer air temperature on autumn NDVI.

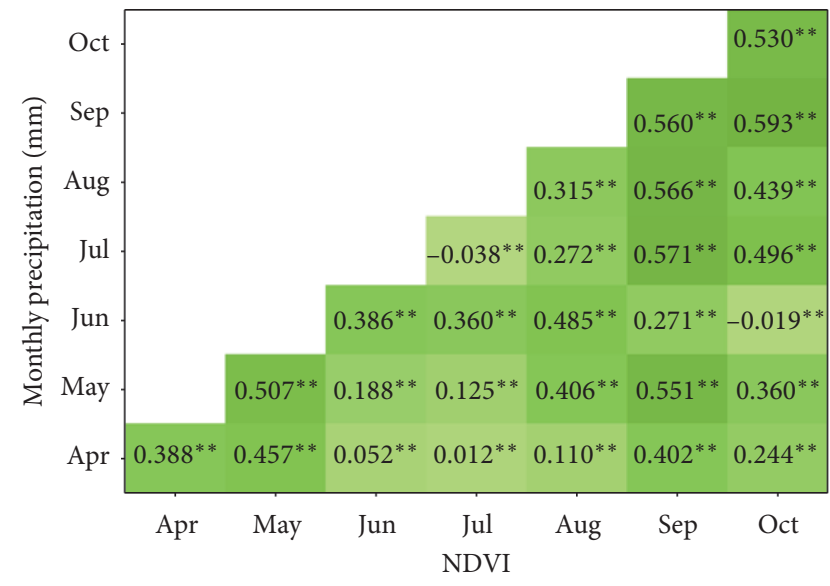

(a)

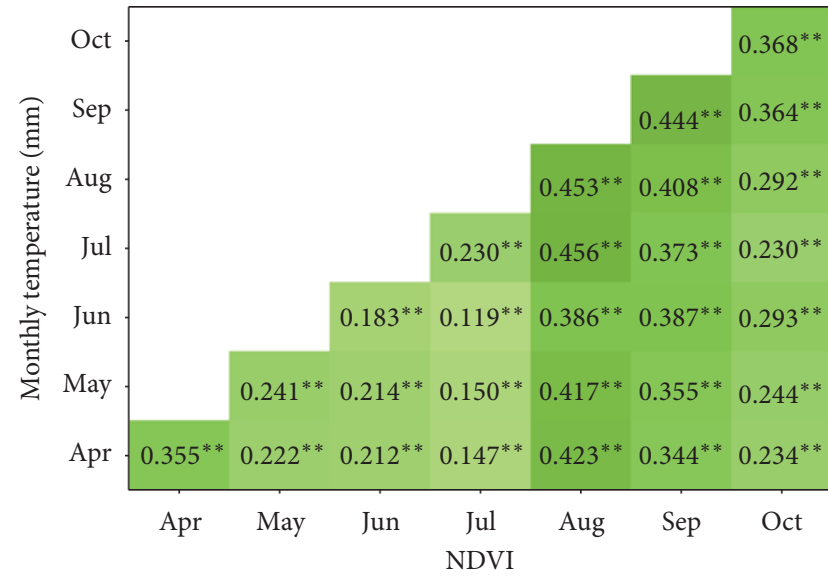

(b)

FiguRE 12: Correlation between monthly NDVI and climatic variables from all previous months from 2001 to $2018 . *$ and $* *$ indicate $P<0.01$ and $P<0.05$, respectively. 
evaporation, and higher soil fertility $[54,55]$. Additionally, the variation of vegetation was extreme in areas where the altitude was more than $4000 \mathrm{~m}$ and the slope was less than $5^{\circ}$, or those that had sunny slopes (southwest, southeast, and south, Figures $4(\mathrm{~d})-4(\mathrm{f}))$. On the one hand, because the ecosystem is fragile and vulnerable to extreme climate at high-altitude areas, the impact of human activities on vegetation is greater in regions with a slope $<5^{\circ}$ [56]. On the other hand, the higher air temperature and increased evaporation of soil moisture lead to soil drought [57]. Finally, the proportion of areas with insignificant decrease in NDVI increased with the increase of altitude (Figure 4(g)) because with the increase of altitude, ecosystems became more vulnerable, and vegetation became more vulnerable to extreme weather [58].

4.2. The Response of the NDVI to Climate Factors. Climate change is one of the main factors affecting the dynamic variation of vegetation. The results of this study showed that the concurrent effects of climate change on the ecosystem were different in different seasons (Figures 8-9). In growing season and autumn, vegetation growth was strongly dominated by air temperature in most areas (Figures 8(a) and 8(d) and Figures 9(a) and 9(d)), which is basically consistent with the findings of previous studies [2]. There are two reasons to explain the above phenomenon. The increase in temperature will stimulate the enzymatic activities of photosynthesis and accelerate the mineralization and decomposition of organic matter [42, 43]. Furthermore, the increased temperature extends the length of the vegetation growing period, leading to more time for vegetation photosynthesis $[1,44,59]$. Another interesting finding is that the precipitation has exerted more effects on NDVI than air temperature in spring. The negative correlations between spring NDVI and spring air temperature were mainly concentrated in the central part of Yunnan Province (Figures 8(b) and 9(b)). The same phenomenon had also been observed in temperate and boreal Eurasia [10], southcentral Indiana [44], and the Tibetan Plateau [60]. On the one hand, the spring vegetation responding to air temperature has a time-lag effect; that is, vegetation will not change immediately with the increase of temperature. On the other hand, Yunnan Province is located in arid and semiarid areas, which are relatively dry in the winter. The precipitation in spring effectively supplements the lack of soil moisture and avoids drought restriction for vegetation [61], thus providing a good hydrothermal environment for vegetation growth.

Vegetation has certain adaptability to climate change. Unless climate change exceeds the vegetation ability to adapt to environmental disturbances, namely, environmental capacity or vegetation tolerance, climate change will not have a significant impact on vegetation $[19,20]$. Time lags generally occur with the change of various climatic factors. However, sometimes even if climatic factors change, vegetation growth can take time to respond, and the time hysteresis will vary depending on different climate factors and different regions because of the delay in the adjustment of biological processes and soil moisture content $[1,19,62-65]$. According to the statistical results of the response of vegetation to climate factors in Yunnan Province, the spring precipitation has an obvious inhibitory effect on summer NDVI and autumn NDVI, and the inhibitory area gradually increased (Figures 10(a) and 10(b) and Figures 11(a) and 11(b)). Yunnan Province is under relative drought in the winter, and the spring precipitation provides a good development environment for seed germination [46]. All these conditions cause vegetation growth to be strongly dominated by spring precipitation. In summer and autumn, with the increased temperature, the water in the soil gradually evaporates, and the spring precipitation does not provide enough water for the growth of summer vegetation and autumn vegetation. In contrast, summer precipitation has a positive effect on autumn vegetation (Figures $10(\mathrm{c})$ and $11(\mathrm{c})$ ). The possible reason is that there is too much precipitation in summer, and some of which still preserved in the soil in autumn, which provides a good water environment for vegetation growth [38]. Compared with the lag effect of precipitation in different seasons on vegetation, temperature significantly promotes vegetation in each season (Figures 10(d)-10(f) and Figures 11(d)-11(f)). This phenomenon contributes to the increase of spring temperature and provides a good thermal environment that makes more seeds germinate. Simultaneously, the increasing temperature provides a basement for the decomposition of organic matter, thus offering a material basis for the growth of vegetation $[9,66]$. Furthermore, we found that precipitation from July to October had a lag effect by 1-2 months on vegetation growth, and temperature from June to August had a lag effect by 1 month on vegetation growth (Figure 12). This phenomenon is closely related to the fact that the precipitation in Yunnan is concentrated in this period owing to the influence of plateau monsoon and the Asian monsoon, and excessive precipitation leads to the necrosis of the root of some vegetation and reduces the photosynthesis of vegetation [38]. Meanwhile, the temperature in Yunnan Province is higher from June to August, which exceeds the optimal temperature of vegetation, resulting in a decrease in the activities of vegetation photosynthesis enzymes [67]. In addition, the higher temperature leads to the smaller stomatal conductance of vegetation, which seriously affects the transpiration of vegetation and the transport of nutrient substances [1].

4.3. Limitations of the Current Study. In this paper, the spatiotemporal distribution of vegetation in Yunnan Province and its response to climate factors were analyzed. Nevertheless, there are some deficiencies in the current study. First, there are many factors that affect vegetation growth. Some changes in vegetation growth are caused by climatic factors; other decisive factors have shown effects on vegetation dynamics, such as the fertilization effect of $\mathrm{CO}_{2}$, and soil properties (soil total carbon, soil total phosphorus, and soil water content) in previous studies. Since the effects of climate factors on soil microbial activities and soil nutrients are closely related to vegetation growth, more 
attention should be paid to the relationship between vegetation and soil factors in future studies. Second, in addition to NDVI, multiple vegetation indices can be used to reflect vegetation dynamics. It is worth noting that the results of vegetation changes may be different due to the differences in resolution and quality of different vegetation dynamic datasets. Therefore, it is necessary to further check whether the data reflecting vegetation dynamics change have the same or similar results and to increase the credibility of the results. Despite these deficiencies in this paper, this work has provided a primary understanding for the spatiotemporal pattern of vegetation in Yunnan Province.

\section{Conclusions}

In the present study, based on the MOD13Q1 NDVI, meteorological stations, and digital elevation model (DEM) data, this paper analyzed the spatiotemporal patterns of vegetation during the past 18 years and its response to climate change using the maximum value composite, Sen's tendency estimation, M-K significance test, CV model, and Pearson correlation coefficient. The temporal variation of the NDVI showed that the NDVI values of different vegetation types increased at different rates, especially in growing season, spring, and autumn. As to spatial patterns, the NDVI increased from the northeast to the southwest. NDVI primarily increased in most regions, which showed degradation in the north and the middle and improvement in the east pattern. Furthermore, the spatial distribution of NDVI, CV, and NDVI trends has strong spatial heterogeneity at different altitudes, slopes, and aspects. Furthermore, an analysis of the climatic factors for vegetation in different seasons showed that vegetation growth in the growing season and autumn was strongly dominated by air temperature, but in spring, it was controlled by precipitation. Finally, the results of lag effects showed that the spring precipitation has an obvious inhibitory effect on summer and autumn NDVI, while the summer precipitation has a positive effect on autumn NDVI. Meanwhile, the lagged effect of the spring and summer air temperature on vegetation was shown as a promotion. The precipitation from July to October had a lag effect by 1-2 months on vegetation growth, and temperature from June to August had a lag effect by 1 month on vegetation growth.

The results of this study revealed the seasonal change of vegetation and emphasized the important role of seasonal precipitation and temperature in controlling vegetation dynamics. Consequently, to better preserve the fragile environment in Yunnan Province, we should pay more attention to the impacts of climate change on vegetation under the condition of global warming.

\section{Data Availability}

The data used to support the findings of the study are available from National Aeronautics and Space Administration (NASA) (https://ladsweb.modaps.eosdis.nasa.gov/andhttps:// asterweb.jpl.nasa.gov/gdem.asp), Data Center of Chinese Academy of Resources and Environmental Sciences (http:// www.resdc.cn/), and Chinese Meteorological Administration (http://data.cma.cn/).

\section{Conflicts of Interest}

The authors declare no conflicts of interest.

\section{Acknowledgments}

The study has been funded by the National Natural Science Foundation of China (41701428), Key R\&D Project of Sichuan Science and Technology Department (Grant no. 2021YFQ0042), the Strategic Priority Research Program of Chinese Academy of Sciences (XDA20030302), the Science and Technology Project of Xizang Autonomous Region (XZ201901-GA-07), National Key R\&D Program of China (2020YFD1100701), IWHR (China Institute of Water Resources and Hydropower Research) National Mountain Flood Disaster Investigation Project (SHZH-IWHR-57), and Young Scholars Development Fund of SWPU (201699010094).

\section{References}

[1] G. Bao, Z. Qin, Y. Bao, Y. Zhou, W. Li, and A. Sanjjav, "NDVIbased long-term vegetation dynamics and its response to climatic change in the Mongolian platea," Remote Sensing, vol. 6, no. 9, pp. 8337-8358, 2014.

[2] Y. Liu and H. Lei, "Responses of natural vegetation dynamics to climate drivers in China from 1982 to 2011," Remote Sensing, vol. 7, no. 8, pp. 10243-10268, 2015.

[3] J. Zhao, S. Huang, Q. Huang et al., "Copula-based abrupt variations detection in the relationship of seasonal vegetationclimate in the Jing river basin, China," Remote Sensing, vol. 11, no. 13, p. 1628, 2019.

[4] X. Yu, S. Ding, Y. Zou, Z. Xue, X. Lyu, and G. Wang, "Review of rapid transformation of floodplain wetlands in northeast China: roles of human development and global environmental change," Chinese Geographical Science, vol. 28, no. 4, pp. 654-664, 2018.

[5] R. A. Dar, S. A. Mir, and S. A. Romshoo, "Influence of geomorphic and anthropogenic activities on channel morphology of river Jhelum in Kashmir valley, NW Himalayas," Quaternary International, vol. 507, pp. 333-341, 2019.

[6] H. Chu, S. Venevsky, C. Wu, and M. Wang, "NDVI-based vegetation dynamics and its response to climate changes at Amur-Heilongjiang river basin from 1982 to 2015," Science of the Total Environment, vol. 650, no. Pt 2, pp. 2051-2062, 2019.

[7] R. B. Myneni, C. J. Tucker, G. Asrar, and C. D. Keeling, "Interannual variations in satellite-sensed vegetation index data from 1981 to 1991," Journal of Geophysical Research: Atmospheres, vol. 103, no. D6, pp. 6145-6160, 1998.

[8] J. Eastman, F. Sangermano, E. Machado, J. Rogan, and A. Anyamba, "Global trends in seasonality of normalized difference vegetation index (NDVI), 1982-2011," Remote Sensing, vol. 5, no. 10, pp. 4799-4818, 2013.

[9] D. Wu, X. Zhao, S. Liang et al., "Time-lag effects of global vegetation responses to climate change," Global Change Biology, vol. 21, no. 9, pp. 3520-3531, 2015.

[10] P. Shilong, X. Wang, P. Ciais et al., "Changes in satellitederived vegetation growth trend in temperate and Boreal Eurasia from 1982 to 2006," Global Change Biology, vol. 17, no. 10, pp. 3228-3239, 2011. 
[11] Y. Zhang, J. Gao, L. Liu, Z. Wang, M. Ding, and X. Yang, "NDVI-based vegetation changes and their responses to climate change from 1982 to 2011: a case study in the Koshi river basin in the middle Himalayas," Global and Planetary Change, vol. 108, pp. 139-148, 2013.

[12] Y. Li, Z. Xie, Y. Qin, and Z. Zheng, "Estimating relations of vegetation, climate change, and human activity: a case study in the $400 \mathrm{~mm}$ annual precipitation fluctuation zone, China," Remote Sensing, vol. 11, no. 10, p. 1159, 2019.

[13] J. Sun, G. Cheng, W. Li, Y. Sha, and Y. Yang, "On the variation of NDVI with the principal climatic elements in the Tibetan plateau," Remote Sensing, vol. 5, no. 4, pp. 1894-1911, 2013.

[14] H. Yunling, L. Tongyan, X. Qiaoli et al., "Spatio-temporal patterns of vegetation coverage and response to hydrothermal factors in Yunnan province, China," Acta Ecologica Sinica, vol. 38, no. 24, pp. 8813-8821, 2018.

[15] X. Liu, X. Zhu, Y. Pan, S. Li, Y. Ma, and J. Nie, "Vegetation dynamics in Qinling-Daba mountains in relation to climate factors between 2000 and 2014," Journal of Geographical Sciences, vol. 26, no. 1, pp. 45-58, 2016.

[16] Y.-G. Li, D. He, J.-M. Hu, and J. Cao, "Variability of extreme precipitation over Yunnan province, China 1960-2012," International Journal of Climatology, vol. 35, no. 2, pp. 245-258, 2015.

[17] J. Xiong, "Analysis of vegetation coverage change in Yunnan province based on MODIS-NDVI," Journal of Geo-Information Science, vol. 20, no. 12, pp. 1830-1840, 2018.

[18] Z.-X. Fan, A. Bräuning, A. Thomas, J.-B. Li, and K.-F. Cao, "Spatial and temporal temperature trends on the Yunnan plateau (southwest China) during 1961-2004," International Journal of Climatology, vol. 31, no. 14, pp. 2078-2090, 2011.

[19] H. Mengqi, F. Mao, H. Sun et al., "Study of normalized difference vegetation index variation and its correlation with climate factors in the three-river-source region," International Journal of Applied Earth Observation and Geoinformation, vol. 13, no. 1, pp. 24-33, 2011.

[20] X. Huang, Z. Tingbin, Y. Guihua et al., "Dynamic changes of NDVI in the growing season of the Tibetan plateau during the past 17 years and its response to climate change," International Journal of Environmental Research and Public Health, vol. 16, no. 18, 2019.

[21] X. Duan, Z. Gu, Y. Li, and H. Xu, "The spatiotemporal patterns of rainfall erosivity in Yunnan province, southwest China: an analysis of empirical orthogonal functions," Global and Planetary Change, vol. 144, pp. 82-93, 2016.

[22] Y. Li, "Drought variability at various timescales over Yunnan province, China: 1961-2015," Theoretical and Applied Climatology, vol. 138, no. 1-2, pp. 743-757, 2019.

[23] Y. Huang, L. Jia, Q. Wang et al., "Cenozoic plant diversity of Yunnan: a review,” Plant Diversity, vol. 38, no. 6, pp. 271-282, 2016.

[24] G. Zhijia, D. Xingwu, L. Bing, H. Jinming, and H. Jiaonan, "The spatial distribution and temporal variation of rainfall erosivity in the Yunnan plateau, southwest China: 1960-2012," Catena, vol. 145, pp. 291-300, 2016.

[25] L. Yu, "Characteristic analysis of precipitation and temperature change trend in Yunnan in recent 46 years," Journal of Catasirophology, vol. 25, pp. 39-44, 2010.

[26] H. Yunling, "Adaptability of vegetation ecosystem to climate change based on the NDVI in Yunnan province, China," Ecological Science, vol. 38, no. 6, pp. 165-172, 2019.

[27] B. N. Holben, "Characteristics of maximum-value composite images from temporal AVHRR data," International Journal of Remote Sensing, vol. 7, no. 11, pp. 1417-1434, 2007.
[28] X. Meng, X. Gao, S. Li, and J. Lei, "Spatial and temporal characteristics of vegetation NDVI changes and the driving forces in Mongolia during 1982-2015," Remote Sensing, vol. 12, no. 4, p. 603, 2020.

[29] T. Whelen and P. Siqueira, "Coefficient of variation for use in crop area classification across multiple climates," International Journal of Applied Earth Observation and Geoinformation, vol. 67, pp. 114-122, 2018.

[30] D. Yingkun, Y. Qin, C. Luo, and L. Tong, "Spatial and temporal variation characteristics of fractional vegetation cover in Qinghai province from 2009 to 2015," in Proceedings of the International Workshop on Earth Observation and Remote Sensing Applications, Guangzhou, China, July 2016.

[31] Y. Wang, X. Shen, M. Jiang, and X. Lu, "Vegetation change and its response to climate change between 2000 and 2016 in marshes of the Songnen plain, northeast China," Sustainability, vol. 12, no. 9, p. 3569, 2020.

[32] D. Jiaqiang, C. Zhao, S. Jianmin et al., "Spatiotemporal changes of vegetation on the Tibetan plateau and relationship to climatic variables during multiyear periods from 1982-2012," Environmental Earth Sciences, vol. 75, no. 1, p. 77, 2015.

[33] C. L. Liang, "NDVI changes of the Nansi lake in Shandong province of China," Advanced Materials Research, vol. 919-921, pp. 1659-1662, 2014.

[34] G. Feng, M. Ma, and W. Shi, "Dynamic changes of vegetation in Karst areas of southwest China during 2001-2016," Guangdong Agricultural Science, vol. 44, no. 12, pp. 94-102, 2017.

[35] Q. Liu and Z. Chen, "Study on spatial and temporal change of vegetation and its impact factors in Yunnan province during 1982-2015," Journal of Kunming University, vol. 40, no. 6, pp. 77-82, 2018.

[36] C. Zhao, "Study on the protection of natural forest and the construction of the project of returning farmland to forest and grass in the western development of Yunnan province," Social Sciences in Yunnan, vol. 1, 2001.

[37] L. Wu, "Problems to be noted in the implementation of the new round of returning farmland to forest project in Yunnan province," Forestry Construction, vol. 2019, no. 1, pp. 43-45, 2019.

[38] C. Ye, J. Sun, M. Liu et al., "Concurrent and lagged effects of extreme drought induce net reduction in vegetation carbon uptake on Tibetan plateau," Remote Sensing, vol. 12, no. 15, p. $2347,2020$.

[39] J. Sun, T. C. Zhou, M. Liu et al., "Water and heat availability are drivers of the aboveground plant carbon accumulation rate in alpine grasslands on the Tibetan plateau," Global Ecology and Biogeography, vol. 29, no. 1, pp. 50-64, 2019.

[40] S. Niu, M. Wu, Y. Han, J. Xia, L. Li, and S. Wan, "Watermediated responses of ecosystem carbon fluxes to climatic change in a temperate steppe," The New Phytologist, vol. 177, no. 1, pp. 209-219, 2008.

[41] C. Gang, W. Zhou, Y. Chen et al., "Quantitative assessment of the contributions of climate change and human activities on global grassland degradation," Environmental Earth Sciences, vol. 72, no. 11, pp. 4273-4282, 2014.

[42] J. M. Melillo, "Soil warming and carbon-cycle feedbacks to the climate system," Science, vol. 298, no. 5601, pp. 2173-2176, 2002.

[43] S. Wan, "Direct and indirect effects of experimental warming on ecosystem carbon processes in a tallgrass prairie," Global Biogeochemical Cycles, vol. 19, no. 2, 2005. 
[44] D. Dragoni, H. P. Schmid, C. A. Wayson, H. Potter, C. S. B. Grimmond, and J. C. Randolph, "Evidence of increased net ecosystem productivity associated with a longer vegetated season in a deciduous forest in south-central Indiana, US," Global Change Biology, vol. 17, no. 2, pp. 886-897, 2011.

[45] Y. Rong, L. Gong, and S. Lu, "Analysis on characteristics and causes of persistent meteorological and hydrological drought in Yunnan from 2009 to 2014," Water Resources Protection, vol. 34, no. 3, pp. 26-33, 2018.

[46] A. Lu, Y. Dong, and C. Jia, "Spatiatemporal characteristics of drought in Yunnan province from 2009 to 201," Guandong Water Resources and Hydropower, vol. 6, pp. 38-41, 2013.

[47] J. Xiong, C. Ye, W. Cheng, L. Guo, C. Zhou, and X. Zhang, "The spatiotemporal distribution of flash floods and analysis of partition driving forces in Yunnan province," Sustainability, vol. 11, no. 10, p. 2926, 2019.

[48] X. Xiao, J. I. Shen, S. G. Haberle et al., "Vegetation, fire, and climate history during the last $18500 \mathrm{cal}$ a BP in south-western Yunnan province, China," Journal of Quaternary Science, vol. 30, no. 8, pp. 859-869, 2015.

[49] C. Hao, S. Wu, and H. Wang, "Analysis on spatio-temporal heterogeneity of vegetation landscape and its cause in southern Yunnan province," Acta Ecologica Sinica, vol. 29, no. 1, pp. 223-230, 2009.

[50] D. Yu, Y.-Z. Pan, X. Liu, and W.-Q. Zhu, "Measurement of ecological capital of ecosystem in Yunnan province based on remote sensed data from 2001 to 2004," in Proceedings of the IEEE International Conference on Geoscience and Remote Sensing Symposium, Denver, CO, USA, August 2007.

[51] Q. Wu and H. Chen, "Urban economic effect region spatial evolution: taking Yunnan province as an example," Acta Ecologica Sinica, vol. 62, no. 12, pp. 1244-1252, 2007.

[52] L. Zhou, "Characteristics and zonality of soil distribution in Yunnan province," Mountain Research, vol. 1, no. 4, pp. 31-38, 1983.

[53] D. He, X. Huang, Q. Tian, and Z. Zhang, "Changes in vegetation growth dynamics and relations with climate in inner Mongolia under more strict multiple pre-processing (2000-2018)," Sustainability, vol. 12, no. 6, p. 2534, 2020.

[54] T. Gao, "Soil nutrient and fertility of different slop directions in the Abies georgei var. Smithii forest in Sejila mountain," Acta Ecologica Sinica, vol. 40, no. 4, pp. 1331-1341, 2020.

[55] M. Liu, "Response of plant element content and soil factors to the slope gradient of alpine meadows in Gannan," Acta Ecologica Sinica, vol. 37, no. 24, pp. 8275-8284, 2017.

[56] J. Xiong, Q. Pang, C. Fan et al., "Spatiotemporal characteristics and driving force analysis of flash floods in Fujian province," ISPRS International Journal of Geo-Information, vol. 9, no. 2, p. 133, 2020.

[57] W. He, C. Ye, J. Sun, J. Xiong, J. Wang, and T. Zhou, "Dynamics and drivers of the alpine timberline on Gongga mountain of Tibetan plateau-adopted from the Otsu method on google earth engine," Remote Sensing, vol. 12, no. 16, p. 2651, 2020.

[58] C. Huang, Y. Li, G. Liu, H. Zhang, and Q. Liu, "Recent climate variability and its impact on precipitation, temperature, and vegetation dynamics in the Lancang river headwater area of China," International Journal of Remote Sensing, vol. 35, no. 8, pp. 2822-2834, 2014.

[59] A. D. Richardson, T. Andy Black, P. Ciais et al., "Influence of spring and autumn phenological transitions on forest ecosystem productivity," Philosophical Transactions of the Royal
Society B: Biological Sciences, vol. 365, no. 1555, pp. 32273246, 2010.

[60] J. Sun and X. Qin, "Precipitation and temperature regulate the seasonal changes of NDVI across the Tibetan plateau," Environmental Earth Sciences, vol. 75, no. 4, p. 291, 2016.

[61] Z.-X. Ye, W.-M. Cheng, Z.-Q. Zhao, J.-Y. Guo, H. Ding, and $\mathrm{N}$. Wang, "Interannual and seasonal vegetation changes and influencing factors in the extra-high mountainous areas of southern Tibet," Remote Sensing, vol. 11, no. 11, p. 1392, 2019.

[62] B. H. Braswell, "The response of global terrestrial ecosystems to interannual temperature variability," Science, vol. 278, no. 5339, pp. 870-873, 1997.

[63] J. Wang, P. M. Rich, and K. P. Price, “Temporal responses of NDVI to precipitation and temperature in the central great plains, USA," International Journal of Remote Sensing, vol. 24, no. 11, pp. 2345-2364, 2010.

[64] P. Shilong, A. Mohammat, J. Fang et al., "NDVI-based increase in growth of temperate grasslands and its responses to climate changes in China," Global Environmental Change, vol. 16, no. 4, pp. 340-348, 2006.

[65] M. L. Davenport and S. E. Nicholson, "On the relation between rainfall and the normalized difference vegetation index for diverse vegetation types in east Africa," International Journal of Remote Sensing, vol. 14, no. 12, pp. 2369-2389, 2007.

[66] Y. Xu and Y. Xi, "Change of vegetation coverage in Jiangsu province and its relation with climatic factors," Bulletin of Soil and Water Conservation, vol. 35, no. 4, pp. 196-201, 2015.

[67] B. Gang, Y. Bao, A. Sanjjav et al., "NDVI-indicated long-term vegetation dynamics in Mongolia and their response to climate change at biome scale," International Journal of Climatology, vol. 35, no. 14, pp. 4293-4306, 2015. 